\title{
Distribution Channel and Remanufacturing Strategy Selection
}

\author{
Xunbo Wu $\mathbb{D}^{1}{ }^{1}$ Yi Wang, ${ }^{2}$ Lingjie Meng, ${ }^{1}$ Wenqi Jiang, ${ }^{1}$ and Ming Wang $\mathbb{D}^{3}$ \\ ${ }^{1}$ School of Economics and Management, Nanjing University of Science and Technology, Nanjing 210094, China \\ ${ }^{2}$ School of Foreign Studies, Nanjing University of Science and Technology, Nanjing 210094, China \\ ${ }^{3}$ College of Economics, Shenzhen University, Shenzhen 518000, China
}

Correspondence should be addressed to Ming Wang; wmtroy@gmail.com

Received 19 December 2020; Accepted 29 April 2021; Published 21 May 2021

Academic Editor: Hiram Ponce

Copyright $\odot 2021$ Xunbo Wu et al. This is an open access article distributed under the Creative Commons Attribution License, which permits unrestricted use, distribution, and reproduction in any medium, provided the original work is properly cited.

\begin{abstract}
Remanufacturing has become an important and fast-growing industry. Many original equipment manufacturers (OEMs) cooperate with third-party remanufacturers (3PRs) through either outsourcing or licensing. They sell the new and remanufactured products either directly to the consumer or indirectly through a retailer. Our study compares the OEM's remanufacturing strategy selection in different distribution channel structures. We demonstrate that outsourcing remanufacturing benefits the OEM when the new products are sold directly and remanufactured products, with a relatively low valuation, are sold indirectly; otherwise, licensing remanufacturing is more beneficial for the OEM. We further find that when consumers perceive the remanufactured products with a sufficiently high value, the selection of remanufacturing strategies benefits consumers, society, and the environment.
\end{abstract}

\section{Introduction}

Remanufacturing, from both a quality and performance perspective, is a controlled and reproducible industrial process by which previously used, worn, or nonfunctional products or parts are revamped to the like-new or betterthan-new condition [1]. There is a general consensus both in academic and industrial fields that remanufacturing, a key part in circular economy, could significantly reduce the discharge of greenhouse gas and energy consumption [1]. As a $\$ 160$ billion industry, remanufacturing generates more than 450,000 jobs worldwide [2]. By recycling and reclaiming products, it saves $85 \%$ of energy, water, and material use, as well as reduces greenhouse gas emissions between $79 \%$ and $99 \%$ compared to traditional manufacturing process [2]. As a crucial conjunction in the circular economy where materials can be part of a continual re-use and recycling system, the remanufacturing sector in the US is estimated to grow at a compound annual growth rate of $6.6 \%$ from 2017 to 2025 [3].

In practice, original equipment manufacturers (OEMs) often rely on third-party remanufacturers (3PRs) to perform remanufacturing operations. Furthermore, there are two different strategies for OEM's remanufacturing operation. One is outsourcing remanufacturing operations, in which the OEM only outsources the remanufacturing operations to a $3 \mathrm{PR}$ and retains the sales of remanufactured products. For example, Land Rover appointed Caterpillar, one of the world's largest remanufacturers, as the preferred provider of global remanufacturing services [4]. The other is licensing remanufacturing business, in which the OEM licenses the whole remanufacturing business (i.e., both remanufacturing and marketing the remanufactured products) to a 3PR. For example, Dell licenses remanufacturing operations and sales of desktop, notebook, server, and storage systems at its Lebanon, TN facility to GENCO ATC $[5,6]$. Foxconn, as a remanufacturer of Apple, not only obtained the right to remanufacture iPhone mobile phones but also got authorization to sell the remanufactured iPhone in China [4]. Besides the different remanufacturing operation strategies, the OEM and 3PR may choose different distribution channels for their products. Specifically, both new and remanufactured products may be sold either directly or indirectly through a retailer. For example, Canon sells its remanufactured products, including PowerShot Digital Cameras, VIXIA Camcorders, and EOS Digital SLR 
Cameras through Canon's online website [7, 8]. Panasonic sells its remanufactured Toughbook computers through several reseller partners, including Bizco, BAYCOM, and Daly Computers $[8,9]$. Motivated by the above practices, we raise our research questions as follows:

(1) What are the implications of the distribution channel (direct selling or indirect selling) on remanufacturing strategy selection (outsourcing or licensing)?

(2) What are the optimal product prices and resulting product sales and profits of different entities?

(3) How does this selection affect consumer surplus, social welfare, and environmental impacts?

To answer our research questions, we build a model wherein an OEM produces a new remanufacturable product and chooses remanufacturing strategies (i.e., outsourcing remanufacturing operation and licensing remanufacturing business). In addition, we consider four distribution channel structures for the marketing of new and remanufactured products: both new and remanufactured products are sold directly, both new and remanufactured products are sold indirectly through a retailer, new products are sold directly (indirectly), and remanufactured products are sold indirectly (directly).

The analysis of our model reveals that the OEM chooses different remanufacturing strategies in different channel structures. Specifically, when the new products are sold directly and remanufactured products, with a relatively low valuation, are sold indirectly, outsourcing remanufacturing is more beneficial for the OEM; otherwise, the OEM prefers to license the remanufacturing business. Furthermore, when consumers perceive the remanufactured products with a sufficiently high value, the selection of remanufacturing strategies benefits consumers, society, and the environment.

The remainder of this study is organized as follows. In Section 2, we briefly summarize the related literature. In Section 3, we describe our model. In Section 4, we derive the optimal equilibrium results and discuss the impact of the distribution channel (direct selling or indirect selling) on remanufacturing strategy selection (outsourcing or licensing). In Section 5, we conclude with a summary of our findings. All proofs and technical details are presented in the appendix.

\section{Literature Review}

Our work studies the remanufacturing strategies in different distribution channel structures, pertaining to three fields of research: remanufacturing strategies, environmental policies, and distribution channel.

The existing literature on remanufacturing strategies can be classified into the following two types: outsourcing remanufacturing operation and licensing remanufacturing business. In terms of outsourcing remanufacturing operations, Savaskan and Bhattacharya [10] studied three modes of collection of used products: direct collection by a manufacturer, outsourcing to an existing retailer, and outsourcing to a third party. They found that the retailer is the most effective undertaker of product collection. Sun et al. [11] compared OEM's in-house remanufacturing with outsourcing remanufacturing to a $3 \mathrm{PR}$. They found that it is more profitable for the OEM to perform remanufacturing operations in-house, but it is more friendly to the environment to outsource remanufacturing to a $3 \mathrm{PR}$. In terms of licensing remanufacturing business, Huang et al. [12] considered a retailer-dominated closed-loop supply chain in which the retailer was licensed to remanufacturing and found that it is crucial for the retailer to reduce the reverse logistic cost coefficient. Ma et al. [13] studied whether an OEM can license a 3PR to remanufacture the used products and found that although it is profitable for an OEM to license the remanufacturing business, it is not always necessary for a 3PR to accept OEMs' authorization. Zou et al. [14] proposed that remanufacturing by technology licensing only benefits the manufacturer but may hurt the supplier and environment. Furthermore, it is more beneficial for remanufacturing to consider customers' environmental awareness. The work by Zou et al. [4] is closely related to our article and worth special mentioning. Zou et al. [4] compared outsourcing remanufacturing with authorization remanufacturing and found that the OEM always obtains higher profit in outsourcing strategy than authorization strategy. However, in our model setting, we find that outsourcing strategy may not always be beneficial to OEM. Zou et al. [4] also found that the 3PR prefers the outsourcing strategy when consumers perceive a high-value remanufactured products, whereas we find that the $3 \mathrm{PR}$ may prefer the outsourcing strategy when consumers perceive a low-value remanufactured product or even regardless of the value of the remanufactured products.

The second stream of literature related to this work is on environmental policies. See Atasu and Van Wassenhove [15] for a comprehensive overview of this topic. Atasu et al. [16] discussed the economic and environmental impacts of extended producer responsibility type of legislation and identified efficiency conditions. Plambeck and Wang [17] investigated the impact of e-waste regulation on new product introduction in a stylized model of the electronics industry. Atasu and Subramanian [18] investigated the implications of collective and individual producer responsibility models of product take-back laws for e-waste on manufacturers' design for product recovery choices and profits and on consumer surplus in the presence of product competition. Esenduran et al. [19] considered three levels of legislation, no take-back legislation, legislation with collection targets, and legislation with collection and reuse targets, characterized the optimal solution for the manufacturer, and analyzed how various levels of legislation affect manufacturing, remanufacturing, and collection decisions. Esenduran et al. [20] examined the effects of environmental policies on three key factors: remanufacturing levels, consumer surplus, and OEM profit.

The other related literature stream investigates the distribution channel choice of a firm. Chiang et al. [21] demonstrated that a manufacturer's direct channel not only increases the profit of the manufacturer by reducing the 
double marginalization but also benefits the retailer by reducing the wholesale price. Cai [22] investigates the influence of channel structures and channel coordination on the supplier, the retailer, and the entire supply chain in the context of two single-channel and two dual-channel supply chains. In terms of channel selection in the closed-loop supply chain, previous literature focuses on the collection of used products from end uses [10, 23-25]. However, there is little research that focuses on the distribution channel structure for the new and remanufactured products' selling. Yan et al. [8] showed that although a manufacturer markets remanufactured products through its own e-channel is greener than through a third party, both manufacturer and retailer may be worse off. Shi et al. [6] considered a firm with separate manufacturing and remanufacturing divisions and an independent retailer and showed that a decentralized firm can benefit from indirect selling through the retailer. In such a channel structure, the firm has more incentive to design a remanufacturable product. In our analysis, we consider the remanufacturing strategy selection when the OEM sells both new and remanufactured products directly, only sells the new products directly, only sells the remanufactured products directly, and sells both products indirectly through a retailer. We compare various circumstances to investigate how the distribution channel (direct selling or indirect selling) affects remanufacturing strategy selection (outsourcing or licensing). To the best of our knowledge, this study is the first to study the impact of the distribution channel on remanufacturing strategy selection.

\section{Model Setup}

We consider the interaction among three profit-maximizing firms: an original equipment manufacturer (OEM or he), a third-party remanufacturer (3PR or she), and a retailer (it).

3.1. The OEM. The OEM, denoted as $M$, designs and produces a new remanufacturable product which has a product $\operatorname{cost} c_{n}$. The OEM has two alternative strategies for the remanufacture business:

(1) Outsourcing remanufacturing operation to a $3 \mathrm{PR}$ (denoted as strategy $j=O$ ), in which the 3PR collects and remanufactures the returned products at cost $c_{r}$ per unit. However, the remarketing operation is still reserved by the OEM. The OEM only pays an outsourcing fee $p_{o}$ to the 3PR for the remanufacturing operation.

(2) Licensing remanufacturing business to a $3 \mathrm{PR}$ (denoted as strategy $j=L$ ), in which the 3PR not only collects and remanufactures the returned products but also remarkets the remanufactured products. The 3PR pays a licensing fee $p_{l}$ to the OEM for the remanufacturing business.

The remanufacturing operations also include cleaning and reassembling the products. All these costs are abstracted by the remanufacturing cost $c_{r}$. To model the sustainability and the environmental friendliness of the remanufacturing operations, we assume $c_{r}<c_{n}[6,23,24]$. This assumption signifies that savings from materials (except for the essential input that needs to be replaced) and assembly of subsystems within the new product dominate the additional costs of disassembly and remanufacturing.

Following the convention in the literature [4, 24, 26, 27], we define $e_{n}$ and $e_{r}$ as the environmental impact of one unit of new product and remanufactured product, respectively. The environmental impact reflects how the products impact the environment in all stages of the product life cycle, including production, use by customers, and end of life. Usually, the environmental impact of a new product is higher than that of a remanufactured product because more material and energy are consumed in the manufacturing operations. Therefore, we assume $e_{n}>e_{r}$.

3.2. The $3 P R$. The $3 P R$, denoted as $R$, collects and remanufactures the returned products at cost $c_{r}$. To derive the key economic insights without introducing unnecessary mathematical complexity, we normalize all other costs to zero.

For modeling convenience and analytical tractability, we consider a single-period model, in which both new and remanufactured products are being sold in the same period. This model can be applied to cases where similar products are introduced to the market repeatedly [10] or where a product's life cycle has reached its maturity stage so that prices, demands, and collection rate are stable $[6,24]$.

3.3. The Retailer. The retailer, denoted as $T$, can sell both new and remanufactured products (if the OEM and the 3PR choose to indirectly sell their products through the retailer) and set the retail prices $p_{n}$ for the new products and $p_{r}$ for the remanufactured products.

We consider four alternative distribution channel structures:

(1) Both the new and remanufactured products are sold directly (denoted as structure $s=D D$ ). Specifically, in strategy $O$, the OEM direct sells both the new and remanufactured products (take Figure 1(a) as a visual illustration). In strategy $L$, the OEM sells the new products directly and the $3 \mathrm{PR}$ sells the remanufactured products directly (see Figure 1(b)).

(2) Only the new products are sold directly (denoted as structure $s=D \bar{D}$ ). Specifically, in strategy $O$, the OEM direct sells the new products and indirectly sells the remanufactured products through the retailer. In strategy $L$, the OEM sells the new products directly and the $3 \mathrm{PR}$ sells the remanufactured products through the retailer. Figures $1(\mathrm{c})$ and $1(\mathrm{~d})$ provide the visual illustration of the two models, respectively.

(3) Only the remanufactured products are sold directly (denoted as structure $s=\bar{D} D$ ). Specifically, in strategy $O$, the OEM sells the new products through the retailer and sells the remanufactured products through his direct channel. In strategy $L$, the OEM sells the new products through the retailer and the 

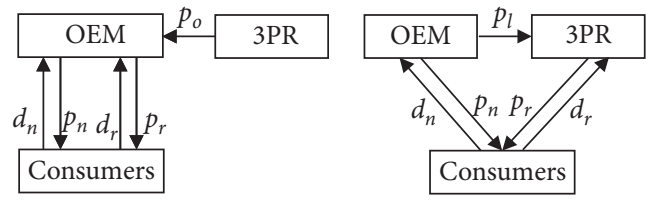

(a)

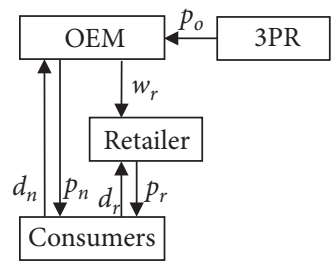

(c)

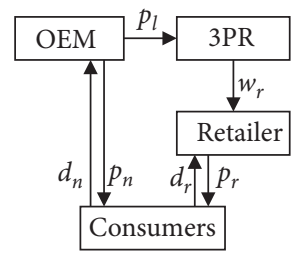

(d)

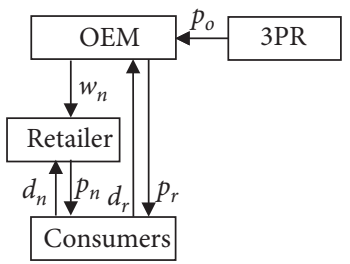

(e)

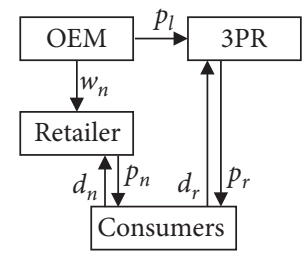

(f)

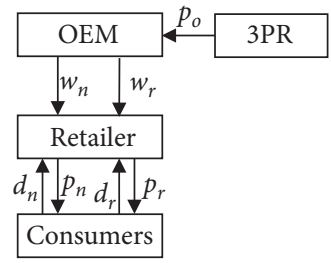

(g)

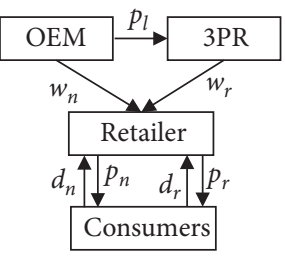

(h)

FIGURE 1: Distribution channel structures and decisions.

3PR sells the remanufactured products directly. The two models are illustrated in Figures 1(e) and 1(f).

(4) Both the new and remanufactured products are sold indirectly (denoted as structure $s=\overline{D D}$ ). Specifically, in strategy $O$, the OEM sells both the new and remanufactured products through the retailer (see Figure $1(\mathrm{~g})$ ). In strategy $L$, the OEM sells the new products indirectly and the 3PR sells the remanufactured products indirectly (see Figure 1(h)).

3.4. Consumers. Consumer willingness-to-pay (WTP) for a new product is heterogeneous and uniformly distributed in the interval $[0,1]$. The market size is normalized to 1 . Consumers typically value the remanufactured product less than the new product $[6,28-30]$. Thus, we assume that if a consumer is willing to pay $\theta$ for a new product, then his WTP for a remanufactured product is $\delta \theta$, where $\delta(0<\delta<1)$ is a discount factor for the remanufactured product. This value discount arises for several reasons. Customers may have an inherent distrust for recovered products. Some customers care about the newness of the product, and thus, they will pay less for a product that is essentially a used one. Moreover, the value discount may also reflect some customers' concern for fairness because product recovery typically costs less than new production.

Each consumer purchases at most one unit of one product (either new products or remanufactured products), i.e., there is no value from consuming a second product. Each consumer chooses the product offering that maximizes her expected surplus which is the difference between WTP and the price. Specifically, consumer $\theta$ has three choices:

(1) Purchasing a new product and realizing the surplus $\theta-p_{n}^{j s}$, where $p_{n}^{j s}$ is the price of the new products

(2) Purchasing a remanufactured product and realizing the surplus $\delta \theta-p_{r}^{j s}$, where $p_{r}^{j s}$ is the price of the remanufactured products

(3) Purchasing nothing and realizing zero surplus
Based on the above assumptions, similar to Zou et al. [4], Shi et al. [6], and Chen and Chen [29], the demand functions for new and remanufactured products are $d_{n}^{j s}=1-\left(\left(p_{n}^{j s}-\right.\right.$ $\left.\left.p_{r}^{j s}\right) /(1-\delta)\right)$ and $d_{r}^{j s}=\left(\delta p_{n}^{j s}-p_{r}^{j s} / \delta(1-\delta)\right)$, where $d_{n}^{j s}$ and $d_{r}^{j s}$ are the demand for new products and the demand for remanufactured products, respectively.

We assume all the parameters are common knowledge for these three players. The key notations are summarized in Table 1.

\section{Model Analysis}

4.1. Distribution Channel Structure DD. In this section, we consider the structure $D D$, in which both the new and remanufactured products are sold directly. Firstly, consider that the OEM outsources remanufacturing operation. Based on the above model description, we can get the profits of the OEM and the 3PR, which are given by

$$
\begin{aligned}
& \Pi_{M}^{O D D}=\left(p_{n}^{O D D}-c_{n}\right) d_{n}^{O D D}+\left(p_{r}^{O D D}-p_{o}^{O D D}\right) d_{r}^{O D D}, \\
& \Pi_{R}^{O D D}=\left(p_{o}^{O D D}-c_{r}\right) d_{r}^{O D D} .
\end{aligned}
$$

The sequence of events is as follows: first, the 3PR decides on the outsourcing fee $p_{o}^{O D D}$. Sequentially, the OEM determines the retail prices $p_{n}^{O D D}$ and $p_{r}^{O D D}$ of the new and remanufactured products, respectively.

Secondly, we consider that the OEM licenses the whole remanufacturing business to the $3 \mathrm{PR}$. In this model, the OEM first decides on the licensing fee $p_{l}^{L D D}$. Then, the OEM and the 3PR maximize their profits by optimizing the retail prices of new and remanufactured products, respectively. The profits of the OEM and the 3PR, which are given by

$$
\begin{aligned}
& \Pi_{M}^{L D D}=\left(p_{n}^{L D D}-c_{n}\right) d_{n}^{L D D}+p_{l}^{L D D} d_{r}^{L D D}, \\
& \Pi_{R}^{L D D}=\left(p_{r}^{L D D}-c_{r}-p_{l}^{L D D}\right) d_{r}^{L D D} .
\end{aligned}
$$

We solve the game backward to ensure subgame perfection. Proposition 1 states the equilibrium solutions in strategy $O$ and strategy $L$. 
TABLE 1: Table of key notation.

\begin{tabular}{|c|c|}
\hline Notation & Description \\
\hline \multicolumn{2}{|c|}{ Superscripts } \\
\hline$j$ & $\begin{array}{c}\text { Type of remanufacturing strategy, } j=O \text { (outsourcing remanufacturing operation to a } 3 \mathrm{PR} \text { ) and } L \text { (licensing remanufacturing } \\
\text { business to a } 3 \mathrm{PR} \text { ) }\end{array}$ \\
\hline$s$ & $\begin{array}{l}\text { Type of distribution channel structure, } s=D D \text { (direct sell the new and remanufactured products), } D \bar{D} \text { (direct sell the new } \\
\text { products and indirect sell the remanufactured products), } \bar{D} D \text { (indirect sell the new products and direct sell the remanufactured } \\
\text { products), and } \overline{D D} \text { (indirect sell the new and remanufactured products) }\end{array}$ \\
\hline \multicolumn{2}{|c|}{ Subscripts } \\
\hline$h$ & Type of product, $h=n$ (new product) and $r$ (remanufactured product) \\
\hline$g$ & Type of player, $g=M$ (original equipment manufacturer), $R$ (third-party remanufacturer), and $T$ (retailer) \\
\hline \multicolumn{2}{|r|}{ (2) } \\
\hline$c_{n}$ & Manufacturing cost per unit \\
\hline$c_{r}$ & Remanufacturing cost per unit \\
\hline$\theta$ & Consumer willingness-to-pay for a product \\
\hline$\delta$ & WTP discount factor for a remanufactured product \\
\hline$e_{h}$ & Unit environmental impact from a product $h$ \\
\hline \\
\hline$w_{h}^{j s}$ & Wholesale price of product $h$ in strategy $j$ and channel structure $s$ \\
\hline$p_{h}^{j s}$ & Retail price of product $h$ in strategy $j$ and channel structure $s$ \\
\hline$p_{o}^{O}$ & Outsourcing fee for remanufacturing operation \\
\hline & License fee for remanufacturing business \\
\hline \multicolumn{2}{|c|}{ Auxiliary variables } \\
\hline$d_{h}^{j s}$ & Product demand for product $h$ in strategy $j$ and channel structure $s$ \\
\hline $\mathrm{CS}^{\mathrm{h} s}$ & Consumer surplus in strategy $j$ and channel structure \\
\hline $\mathrm{SW}^{\text {js }}$ & Social welfare in strategy $j$ and channel structure $s$ \\
\hline $\mathrm{EI}^{j s}$ & Total environmental impact in strategy $j$ and channel structure $s$ \\
\hline \multicolumn{2}{|c|}{ Objective function values } \\
\hline$\Pi_{M}^{j s}$ & OEM's profit in strategy $j$ and channel structure $s$ \\
\hline$\Pi_{R}^{j s}$ & 3PR's profit in strategy $j$ and channel structure $s$ \\
\hline$\Pi_{T}^{j s}$ & Retailer's profit in strategy $j$ and channel structure $s$ \\
\hline
\end{tabular}

Proposition 1. In the channel structure DD, the equilibrium solutions are summarized in Table 2.

Proposition 1 states the equilibrium solutions in structure $D D$. According to this, we compare the OEM's equilibrium results, which lead to Corollary 1. For easy interpretation, we define the unit marginal profits of new products for the OEM as $m p_{n}^{O D D}=p_{n}^{O D D}-c_{n}$ in strategy $O$ and $m p_{n}^{L D D}=p_{n}^{L D D}-c_{n}$ in strategy $L$, respectively. The unit marginal profits of remanufactured products for the OEM are $m p_{r}^{O D D}=p_{r}^{O D D}-p_{o}^{O D D}$ in strategy $O$ and $m p_{r}^{L D D}=p_{l}^{L D D}$ in strategy $L$, respectively.

\section{Corollary 1. In the channel structure DD,}

(1) The unit marginal profit of new products for the OEM in strategy $O$ is lower than the profit in strategy $L$. Formally, $\quad m p_{n}^{O D D}-m p_{n}^{L D D}=-\left(\left(\delta c_{n}-c_{r}\right) /(8\right.$ $+\delta))<0$.

(2) The unit marginal profit of remanufactured products for the OEM in strategy $O$ is lower than the profit in strategy L. Formally, $m p_{r}^{O D D}-m p_{r}^{L D D}=-(((8$ $\left.\left.-\delta)\left(\delta c_{n}-c_{r}\right)\right) /(4(8+\delta))\right)<0$.

(3) The demand for new products in strategy $O$ is higher than the demand in strategy L. Formally, $d_{n}^{O D D}-$ $d_{n}^{L D D}=\left(\left((4-\delta)\left(\delta c_{n}-c_{r}\right)\right) /(4(8+\delta)(1-\delta))\right)>0$.
(4) The demand for remanufactured products in strategy $p_{n}^{O D D} O$ is lower than the demand in strategy $L$. Formally, $d_{r}^{O D D}-d_{r}^{L D D}=-\left(\left(3\left(\delta c_{n}-c_{r}\right)\right) /(4(8+\delta)\right.$ $(1-\delta)))<0$.

Corollary 1 demonstrates that, for the OEM, when he chooses to license the whole remanufacturing business to the 3PR rather than only outsource the remanufacturing operations, he can get higher unit marginal profits from both the new and remanufactured products. Furthermore, the 3PR produces more remanufactured products, which further increases the OEM's profit from licensing. The cons of licensing for the OEM is licensing leads to the 3PR gains the whole control for the remanufacturing business. Thus, the new product would face more intense retail competition. The OEM cuts back on the production of new products.

Next, we characterize the conditions for the OEM to choose different remanufacturing strategies in structure $D D$. By comparing strategy $O$ with strategy $L$, we derive the following proposition.

Proposition 2. In the channel structure $D D$,

(1) The OEM's profit in strategy $O$ is lower than the profit in strategy L. Formally, $\Pi_{M}^{O D D}-\Pi_{M}^{L D D}=-((8$ $\left.\left.-\delta)\left(\delta c_{n}-c_{r}\right)=\right)^{2} / 16(\delta+8)(1-\delta) \delta\right)<0$. 
TABLE 2: Equilibrium solutions in structure $D D$

\begin{tabular}{lcc}
\hline Optimal solutions & Strategy $O$ & Strategy $L$ \\
\hline$p_{o}^{O D D}\left(p_{l}^{L D D}\right)$ & $\left(\delta c_{n}+c_{r}\right) / 2$ & $\left(\delta^{2}\left(1-c_{n}\right)+8\left(\delta-c_{r}\right)\right) /(2(8+\delta))$ \\
$p_{n}^{O D D}\left(p_{n}^{L D D}\right)$ & $\left(1+c_{n}\right) / 2$ & $\left(\left(1+c_{n}\right) / 2\right)+\left(\left(\delta c_{n}-c_{r}\right) /(8+\delta)\right)$ \\
$p_{r}^{O D D}\left(p_{r}^{L D D}\right)$ & $\left(2 \delta+\delta c_{n}+c_{r}\right) / 4$ & $(\delta / 2)+\left(\left(\delta^{2} c_{n}+4 \delta c_{n}+4 c_{r}\right) /(2(8+\delta))\right)$ \\
$d_{n}^{O D D}\left(d_{n}^{L D D}\right)$ & $\left(\left(2-c_{n}\right) / 4\right)-\left(\left(c_{n}-c_{r}\right) /(4(1-\delta))\right)$ & $(1 / 2)+\left(\left(\delta^{2} c_{n}+\delta c_{n}-8 c_{n}+6 c_{r}\right) /(2(1-\delta)(8+\delta))\right)$ \\
$d_{r}^{O D D}\left(d_{r}^{L D D}\right)$ & $\left(\delta c_{n}-c_{r}\right) /(4(1-\delta) \delta)$ & $\left((2+\delta)\left(\delta c_{n}-c_{r}\right)\right) /((8+\delta)(1-\delta) \delta)$ \\
$\Pi_{M}^{O D D}\left(\Pi_{M}^{L D D}\right)$ & $\left(\left(\delta c_{n}-c_{r}\right)^{2} /(16(1-\delta) \delta)\right)+\left(\left(1-c_{n}\right)^{2} / 4\right)$ & $\left(\left(\delta c_{n}-c_{r}\right)^{2} /(8+\delta)(1-\delta) \delta\right)+\left(\left(1-c_{n}\right)^{2} / 4\right)$ \\
$\prod_{R}^{O D D}\left(\prod_{R}^{L D D}\right)$ & $\left(\delta c_{n}-c_{r}\right)^{2} /(8(1-\delta) \delta)$ & $\left((2+\delta)^{2}\left(\delta c_{n}-c_{r}\right)^{2}\right) /\left((8+\delta)^{2}(1-\delta) \delta\right)$ \\
\hline
\end{tabular}

(2) The 3PR's profit in strategy $O$ is higher than the profit in strategy L. Formally, $\Pi_{R}^{O D D}-\Pi_{R}^{L D D}=\left(\left(\left(32-7 \delta^{2}-\right.\right.\right.$ $16 \delta)\left(\left(\delta c_{n}-c_{r}\right)^{2} /\left(8(\delta+8)^{2}(1-\delta) \delta\right)\right)>0$.

According to Proposition 2, we find that the OEM always chooses to license the remanufacturing to the $3 \mathrm{PR}$ in the channel structure $D D$. The reason is, as demonstrated in Corollary 1, licensing can lead to higher marginal profits from both new and remanufactured products and larger production from remanufactured products. However, the OEM's choice makes the $3 \mathrm{PR}$ get worse (i.e., $\left.\Pi_{R}^{L D D}-\Pi_{R}^{O D D}<0\right)$.

4.2. Distribution Channel Structure $D \bar{D}$. In this section, we consider the structure $D \bar{D}$, in which only the new products are sold directly. Firstly, consider that the OEM outsources remanufacturing operation. Based on the above model description, we can get the profits of the OEM, the 3PR, and the retailer, which are given by

$$
\begin{aligned}
& \Pi_{M}^{O D \bar{D}}=\left(p_{n}^{O D \bar{D}}-c_{n}\right) d_{n}^{O D \bar{D}}+\left(w_{r}^{O D \bar{D}}-p_{o}^{O D \bar{D}}\right) d_{r}^{O D \bar{D}}, \\
& \Pi_{R}^{O D \bar{D}}=\left(p_{o}^{O D \bar{D}}-c_{r}\right) d_{r}^{O D \bar{D}}, \\
& \Pi_{T}^{O D \bar{D}}=\left(0 p_{r}^{O D \bar{D}}-w_{r}^{O D \bar{D}}\right) d_{r}^{O D \bar{D}} .
\end{aligned}
$$

The sequence of events is as follows: first, the $3 \mathrm{PR}$ decides on the outsourcing fee $p_{o}^{O D \bar{D}}$. Secondly, the OEM determines the retail price $p_{n}^{O D \bar{D}}$ of the new products and the wholesale price $w_{r}^{O D D}$ of the remanufactured products to the retailer. Finally, the retailer determines the retail price $p_{r}^{O D \bar{D}}$ of the remanufactured products.

Secondly, we consider that the OEM licenses the whole remanufacturing business to the $3 \mathrm{PR}$. In this model, the OEM first decides on the licensing fee $p_{l}^{L D \bar{D}}$. Then, according to $p_{l}^{L D \bar{D}}$, the $3 \mathrm{PR}$ maximizes her profit by optimizing the wholesale price $w_{r}^{L D \bar{D}}$ of the remanufactured products to the retailer. Thirdly, the retailer determines the prices of the new and remanufactured products, respectively. The profits of the $\mathrm{OEM}$, the $3 \mathrm{PR}$, and the retailer, which are given by

$$
\begin{aligned}
& \Pi_{M}^{L D \bar{D}}=\left(p_{n}^{L D \bar{D}}-c_{n}\right) d_{n}^{L D \bar{D}}+p_{l}^{L D \bar{D}} d_{r}^{L D \bar{D}}, \\
& \Pi_{R}^{L D \bar{D}}=\left(w_{r}^{L D \bar{D}}-c_{r}-p_{l}^{L D \bar{D}}\right) d_{r}^{L D \bar{D}}, \\
& \Pi_{T}^{L D \bar{D}}=\left(p_{r}^{L D \bar{D}}-w_{r}^{L D \bar{D}}\right) d_{r}^{L D \bar{D}} .
\end{aligned}
$$

Similarly, we use backward induction to ensure subgame perfection. Proposition 3 states the equilibrium solutions in strategy $O$ and strategy $L$.

Proposition 3. In the channel structure $D \bar{D}$, the equilibrium solutions are summarized in Table 3.

According to Proposition 3, we compare the OEM's equilibrium results, which lead to Corollary 2. Similarly, we define the unit marginal profits of new products for the OEM as $m p_{n}^{O D \bar{D}}=p_{n}^{O D \bar{D}}-c_{n}$ in strategy $O$ and $m p_{n}^{L D \bar{D}}=p_{n}^{L D \bar{D}}-$ $c_{n}$ in strategy $L$, respectively. The unit marginal profits of remanufactured products for the OEM are $m p_{r}^{O D \bar{D}}$ $=w_{r}^{O D \bar{D}}-p_{o}^{O D \bar{D}}$ in strategy $O$ and $m p_{r}^{L D \bar{D}}=p_{l}^{L D \bar{D}}$ in strategy $L$, respectively.

\section{Corollary 2. In the channel structure $D \bar{D}$}

(1) The unit marginal profit of new products for the OEM in strategy $O$ is lower than the profit in strategy $L$. Formally, $m p_{n}^{O D \bar{D}}-m p_{n}^{L D \bar{D}}=-\left(\left((3-\delta)(2-\delta)\left(\delta c_{n}\right.\right.\right.$ $\left.\left.\left.-c_{r}\right)\right) /\left(2\left(\delta^{3}-3 \delta^{2}-5 \delta+16\right)\right)\right)<0$.

(2) The unit marginal profit of remanufactured products for the OEM in strategy $O$ is lower than the profit in strategy L. Formally, $m p_{r}^{O D \bar{D}}-m p_{r}^{L D \bar{D}}=-\left(\left(\left(\delta^{3}-\right.\right.\right.$ $\left.\left.\left.9 \delta^{2}+23 \delta-16\right)\left(\delta c_{n}-c_{r}\right)\right) /\left(4\left(\delta^{3}-3 \delta^{2}-5 \delta+16\right)\right)\right)<0$.

(3) The demand for new products in strategy $O$ is higher than the demand in strategy L. Formally, $d_{n}^{O D D}-$ $d_{n}^{L D D}=\left(\left(\left(\delta^{3}-11 \delta^{2}+31 \delta-24\right) \quad\left(\delta c_{n}-c_{r}\right)\right) /(8(\delta\right.$ $\left.\left.-1)\left(\delta^{3}-3 \delta^{2}-5 \delta+16\right)\right)\right)>0$.

(4) The demand for remanufactured products in strategy $p_{n}^{O D D} O$ is lower than the demand in strategy $L$. Formally, $\quad d_{r}^{O D D}-d_{r}^{L D D}=-\left(\left(\left[3 \delta^{2}+13(1\right.\right.\right.$ $\left.\left.-\delta)]\left(\delta c_{n}-c_{r}\right)\right) /\left(8(1-\delta)\left(\delta^{3}-3 \delta^{2}-5 \delta+16\right)\right)\right)<0$.

As the same as the structure $D D$, the OEM can get higher unit marginal profits from both new and remanufactured products and a larger demand from remanufactured products in strategy $L$ and structure $D \bar{D}$. Interestingly, we find that the OEM may not always choose to license the whole remanufacturing business to the $3 \mathrm{PR}$. This is summarized in the following proposition.

Proposition 4. In the channel structure $D \bar{D}$,

(1) The OEM's profit in strategy $O$ is lower than the profit in strategy $L$ if $\delta>\delta_{1}$; otherwise, the profit in strategy 
TABLE 3: Equilibrium solutions in structure $D \bar{D}$

\begin{tabular}{|c|c|c|}
\hline $\begin{array}{l}\text { Optimal } \\
\text { solutions }\end{array}$ & trategy $O$ & Strategy $L$ \\
\hline $\begin{array}{l}p_{o}^{O D \bar{D}}\left(p_{l}^{L D \bar{D}}\right) \\
w_{r}^{O D \bar{D}}\left(w_{r}^{L D \bar{D}}\right) \\
p_{n}^{O D \bar{D}}\left(p_{n}^{L D \bar{D}}\right) \\
p_{r}^{O D \bar{D}}\left(p_{r}^{L D \bar{D}}\right) \\
d_{n}^{O D \bar{D}}\left(d_{n}^{L D \bar{D}}\right) \\
d_{r}^{O D \bar{D}}\left(d_{r}^{L D} \bar{D}\right) \\
\Pi_{M}^{O D \bar{D}}\left(\Pi_{M}^{L D} \bar{D}\right) \\
\Pi_{R}^{O D \bar{D}}\left(\Pi_{R}^{L D} \bar{D}\right) \\
\prod_{T}^{O D \bar{D}}\left(\Pi_{T}^{L D} \bar{D}\right)\end{array}$ & $\begin{array}{c}\left(\delta c_{n}+c_{r}\right) / 2 \\
\left(2 \delta+\delta c_{n}+c_{r}\right) / 4 \\
\left(1+c_{n}\right) / 2 \\
\left(4 \delta+3 \delta c_{n}+c_{r}\right) / 8 \\
\left(\left(1-c_{n}\right) / 2\right)-\left(\left(\delta c_{n}-c_{r}\right) /(8(1-\delta))\right) \\
\left(\delta c_{n}-c_{r}\right) /(8(1-\delta) \delta) \\
\left(\left(1-c_{n}\right)^{2} / 4\right)+\left(\left(\delta c_{n}-c_{r}\right)^{2} /(32(1-\delta) \delta)\right) \\
\left(\delta c_{n}-c_{r}\right)^{2} /(16(1-\delta) \delta) \\
\left(\delta c_{n}-c_{r}\right)^{2} /(64(1-\delta) \delta)\end{array}$ & $\begin{array}{c}\left(\left(\delta\left(1-c_{n}\right)\right) / 2\right)+\left(\left((2-\delta)(8-3 \delta)\left(\delta c_{n}-c_{r}\right)\right) / 2\left(\delta^{3}-3 \delta^{2}-5 \delta+16\right)\right) \\
\left(\left(\delta+c_{r}\right) / 2\right)+\left(\left((8-3 \delta)\left(\delta c_{n}-c_{r}\right)\right) /\left(2\left(\delta^{3}-3 \delta^{2}-5 \delta+16\right)\right)\right) \\
\left(\left(1+c_{n}\right) / 2\right)+\left(\left((3-\delta)(2-\delta)\left(\delta c_{n}-c_{r}\right)\right) /\left(2\left(\delta^{3}-3 \delta^{2}-5 \delta+16\right)\right)\right) \\
\left(\left(\delta\left(1+c_{n}\right)\right) / 2\right)-\left(\left((2-\delta)^{2}\left(\delta c_{n}-c_{r}\right)\right) /\left(2\left(\delta^{3}-3 \delta^{2}-5 \delta+16\right)\right)\right) \\
\left(\left(1-c_{n}\right) / 2\right)-\left(\left((2-\delta)(5-2 \delta)\left(\delta c_{n}-c_{r}\right)\right) /\left(2\left(\delta^{3}-3 \delta^{2}-5 \delta+16\right)(1-\delta)\right)\right) \\
\left((2-\delta)\left(2-\delta^{2}+2 \delta\right)\left(\delta c_{n}-c_{r}\right)\right) /\left(2\left(\delta^{3}-3 \delta^{2}-5 \delta+16\right)(1-\delta) \delta\right) \\
\left(\left(1-c_{n}\right)^{2} / 4\right)+\left(\left((2-\delta)^{2}\left(\delta c_{n}-c_{r}\right)^{2}\right) /\left(4\left(\delta^{3}-3 \delta^{2}-5 \delta+16\right)(1-\delta) \delta\right)\right) \\
\left((2-\delta)(4-\delta)\left(\delta^{2}-2 \delta-2\right)^{2}\left(\delta c_{n}-c_{r}\right)^{2}\right) /\left(4\left(\delta^{3}-3 \delta^{2}-5 \delta+16\right)^{2}(1-\delta) \delta\right) \\
\left((2-\delta)^{2}\left(\delta^{2}-2 \delta-2\right)^{2}\left(\delta c_{n}-c_{r}\right)^{2}\right) /\left(4\left(\delta^{3}-3 \delta^{2}-5 \delta+16\right)^{2}(1-\delta) \delta\right)\end{array}$ \\
\hline
\end{tabular}

$O$ is higher than that in strategy L. Formally, $\Pi_{M}^{O D \bar{D}}-$ $\Pi_{M}^{L D \bar{D}}=-\left(\left(\left(\delta^{3}-11 \delta^{2}+27 \delta-16\right)\left(\delta c_{n}-c_{r}\right)^{2}\right) /\right.$ $\left.\left(32\left(\delta^{3}-3 \delta^{2}-5 \delta+16\right)(1-\delta) \delta\right)\right)<0$ if $\delta>\delta_{1}$ and $\Pi_{M}^{O D \bar{D}}-\Pi_{M}^{L D \bar{D}} \geq 0$ if $\delta \leq \delta_{1}$, where $\delta_{1} \in(0,1)$ is defined as the real root of the cubic equation: $\delta^{3}-11 \delta^{2}+27 \delta-16=0$.

(2) The 3PR's profit in strategy $O$ is lower than the profit in strategy $L$ if $\delta>\delta_{2}$; otherwise, the profit in strategy $O$ is higher than that in strategy L. Formally, $\Pi_{R}^{O D D}-$ $\Pi_{R}^{L D \bar{D}}=-\left(\left(\left(3 \delta^{6}-34 \delta^{5}+129 \delta^{4}-158 \delta^{3}-105 \delta^{2}+\right.\right.\right.$ $\left.320 \delta-128)\left(\delta c_{n}-c_{r}\right)^{2}\right) /\left(16\left(\delta^{3}-3 \delta^{2}-5 \delta\right.\right.$ $\left.\left.+16)^{2}(1-\delta) \delta\right)\right)<0$ if $\delta>\delta_{2}$ and $\Pi_{R}^{O D \bar{D}}-\Pi_{R}^{L D \bar{D}} \geq 0$ if $\delta \leq \delta_{2}$, where $\delta_{2} \in(0,1)$ is defined as the real root of the sixth degree equation: $3 \delta^{6}-34 \delta^{5}+129 \delta^{4}-158 \delta$ $3-105 \delta^{2}+320 \delta-128=0$.

(3) The retailer's profit in strategy $O$ is lower than the profit in strategy L. Formally, $\Pi_{T}^{O D \bar{D}}-\Pi_{T}^{L D \bar{D}}=-\left(\left(\left(15 \delta^{5}-122 \delta^{4}+321 \delta^{3}-190 \delta^{2}\right.\right.\right.$ $\left.-377 \delta+416)\left(\delta c_{n}-c_{r}\right) \quad 2\right) /\left(64\left(\delta^{3}-3 \delta^{2}-5 \delta+\right.\right.$ $\left.\left.16)^{2}(1-\delta)\right)\right)<0$.

Proposition 4 illustrates that, in the structure $D \bar{D}$, when the WTP discount factor for a remanufactured product is sufficiently low (i.e., $\delta \leq \delta_{1}$ ), the OEM chooses to only outsource the remanufacturing operation to the $3 \mathrm{PR}$. The reason is that the OEM produces larger new products when he adopts strategy $O$ and the benefits of larger new products outweigh the disadvantages of lower margin profits when the WTP discount factor is low. From the 3PR's perspective, the OEM's choice makes the 3PR worse when the WTP discount factor is in a midrange (i.e., $\delta_{2}<\delta<\delta_{1}$ ). Specifically, when the WTP discount factor is sufficiently low (i.e., $\delta \leq \delta_{2}$ ), the OEM adopts strategy $O$ and the $3 P R$ realizes a higher profit (i.e., $\Pi_{R}^{O D D}-\Pi_{R}^{L D D}>0$ when $\delta \leq \delta_{2}$ ). When the WTP discount factor is sufficiently high (i.e., $\delta \geq \delta_{1}$ ), the OEM adopts strategy $L$ and the 3 PR realizes a higher profit (i.e., $\Pi_{R}^{L D D}-$ $\Pi_{R}^{O D D}>0$ when $\delta \geq \delta_{1}$ ). From the retailer's perspective, the OEM's choice makes the retailer worse when the WTP discount factor is low (i.e., $\Pi_{T}^{O D \bar{D}}-\Pi_{T}^{L D \bar{D}}<0$ ).

4.3. Distribution Channel Structure $\bar{D} D$. In this section, we consider the structure $\bar{D} D$, in which only the remanufactured products are sold directly. Firstly, consider that the
OEM outsources remanufacturing operation. Based on the above model description, we can get the profits of the OEM, the $3 \mathrm{PR}$, and the retailer, which are given by

$$
\begin{aligned}
& \Pi_{M}^{O \bar{D} D}=\left(w_{n}^{O \bar{D} D}-c_{n}\right) d_{n}^{O \bar{D} D}+\left(p_{r}^{O \bar{D} D}-p_{o}^{O \bar{D} D}\right) d_{r}^{O \bar{D} D}, \\
& \Pi_{R}^{O \bar{D} D}=\left(p_{o}^{O \bar{D} D}-c_{r}\right) d_{r}^{O \bar{D} D}, \\
& \Pi_{T}^{O \bar{D} D}=\left(p_{n}^{O \bar{D} D}-w_{n}^{O \bar{D} D}\right) d_{n}^{O \bar{D} D} .
\end{aligned}
$$

The sequence of events is as follows: first, the 3PR decides on the outsourcing fee $p_{o}^{O \bar{D} D}$. Secondly, the OEM determines the retail price $p_{r}^{O D D}$ of the remanufactured products and the wholesale price $w_{n}^{O \bar{D} D}$ of the new products to the retailer. Finally, the retailer determines the retail price $p_{n}^{O \bar{D} D}$ of the new products.

Secondly, we consider that the OEM licenses the whole remanufacturing business to the $3 \mathrm{PR}$. In this model, the OEM first decides on the licensing fee $p_{l}^{L \bar{D} D}$ and the wholesale price $w_{n}^{L \bar{D} D}$. Sequentially, the 3PR maximizes her profit by optimizing the retail price $p_{r}^{L \bar{D} D}$ of the remanufactured products. Simultaneously, the retailer determines the price $p_{n}^{L \bar{D} D}$ of the new products. The profits of the OEM, the $3 \mathrm{PR}$, and the retailer, which are given by

$$
\begin{aligned}
& \Pi_{M}^{L \bar{D} D}=\left(w_{n}^{L \bar{D} D}-c_{n}\right) d_{n}^{L \bar{D} D}+p_{l}^{L \bar{D} D} d_{r}^{L \bar{D} D}, \\
& \Pi_{R}^{L \bar{D} D}=\left(p_{r}^{L \bar{D} D}-c_{r}-p_{l}^{L \bar{D} D}\right) d_{r}^{L \bar{D} D}, \\
& \Pi_{T}^{L \bar{D} D}=\left(p_{n}^{L \bar{D} D}-w_{n}^{L \bar{D} D}\right) d_{n}^{L \bar{D} D} .
\end{aligned}
$$

Similarly, we use backward induction to ensure subgame perfection. Proposition 5 states the equilibrium solutions in strategy $O$ and strategy $L$.

Proposition 5. In the channel structure $\bar{D} D$, the equilibrium solutions are summarized in Table 4.

According to Proposition 5, we compare the OEM's equilibrium results, which lead to Corollary 3 . In the same manner, we define the unit marginal profits of new products for the OEM as $m p_{n}^{O \bar{D} D}=w_{n}^{O D D}-c_{n}$ in strategy $O$ and $m p_{n}^{L \bar{D} D}=w_{n}^{L \bar{D} D}-c_{n}$ in strategy $L$, respectively. The unit 


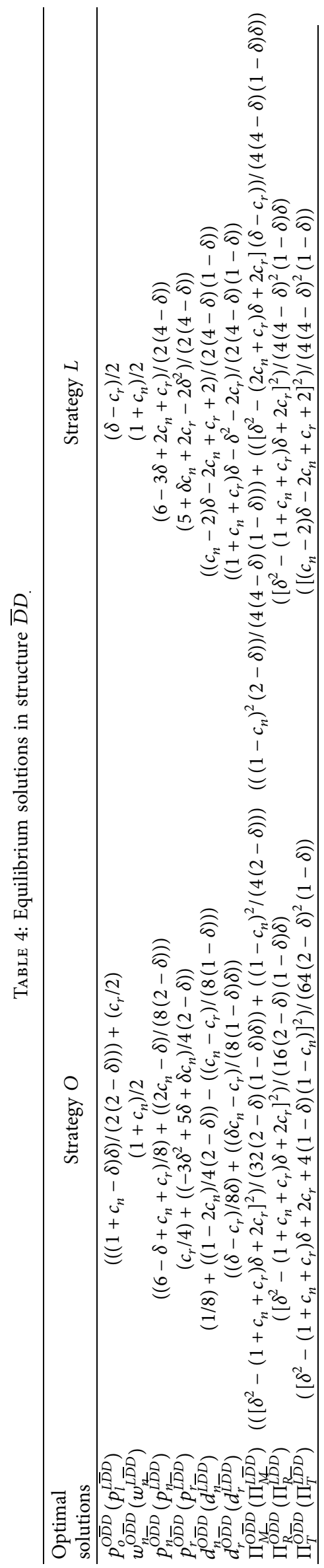


marginal profits of remanufactured products for the OEM are $m p_{r}^{O \bar{D} D}=p_{r}^{O \bar{D} D}-p_{o}^{O \bar{D} D}$ in strategy $O$ and $m p_{r}^{L \bar{D} D}=p_{l}^{L \bar{D} D}$ in strategy $L$, respectively.

Corollary 3. In the channel structure $\bar{D} D$,

(1) The unit marginal profit of new products for the OEM in strategy $O$ is the same as the profit in strategy $L$.

(2) The unit marginal profit of remanufactured products for the OEM in strategy $O$ is higher than the profit in strategy $L$ if $\delta<\delta_{3}$ and is lower than the profit in strategy $L$ if $\delta \geq \delta_{3}$. Formally, $m p_{r}^{O \bar{D} D}$ $-m p_{r}^{L D D}=\left(\delta^{2}-\left(c_{n}+c_{r}+1\right) \delta+2 c_{r}\right) /(4(2-\delta))>0$ if $\delta<\delta_{3}$ and $m p_{r}^{O \bar{D} D}-m p_{r}^{L \bar{D} D} \leq 0$ if $\delta \geq \delta_{3}$, which is defined as the real root of the quadratic equation: $\delta^{2}-\left(c_{n}+c_{r}+1\right) \delta+2 c_{r}$.

(3) The demand for new products in strategy $O$ is lower than the demand in strategy if $\delta<\delta_{3}$ and is higher than the demand in strategy $L$ if $\delta \geq \delta_{3}$. Formally, $d_{n}^{O \bar{D} D}-d_{n}^{L \bar{D} D}=-\left(\left(\left[\delta^{2}-\left(c_{n}+c_{r}+1\right) \delta+\right.\right.\right.$ $\left.\left.\left.2 c_{r}\right] \delta\right) /(8(4-\delta)(2-\delta)(1-\delta))\right)<0$ if $\delta<\delta_{3}$ and $d_{n}^{O D D}-d_{n}^{L \bar{D} D} \geq 0$ if $\delta \geq \delta_{3}$.

(4) The demand for remanufactured products in strategy $O$ is higher than the demand in strategy $L$ if $\delta<\delta_{3}$ and is lower than the demand in strategy $L$ if $\delta \geq \delta_{3}$. Formally, $\quad d_{r}^{O \bar{D} D}-d_{r}^{L \bar{D} D}=\left(\delta^{2}-\left(c_{n}+c_{r}+1\right) \delta+\right.$ $\left.2 c_{r}\right) /(8(4-\delta)(1-\delta))>0$ if $\delta<\delta_{3}$ and $d_{r}^{O D D} D_{-}$ $d_{r}^{L D D} \leq 0$ if $\delta \geq \delta_{3}$.

Different from the structure $D D$ and $D \bar{D}$, in the channel structure $\bar{D} D$, the OEM earns a constant unit marginal profit from new products no matter what remanufacturing strategy the OEM chooses. With a low WTP discount factor (i.e., $\delta<\delta_{3}$ ), the OEM earns a higher unit marginal profit from remanufactured products in strategy $O$ and the demand for remanufactured products is higher in strategy $O$. However, the OEM produces smaller new products in strategy $O$. With a high WTP discount factor (i.e., $\delta \geq \delta_{3}$ ), the OEM earns a lower unit marginal profit from remanufactured products in strategy $O$ and the demand for remanufactured products is lower in strategy $O$. However, the OEM produces larger new products in strategy $O$. An intriguing result is that different changes in unit marginal profit and demand may cause the OEM to always choose the same remanufacturing strategy, as Proposition 6 presents.

Proposition 6. In the channel structure $\bar{D} D$,

(1) The OEM's profit in strategy $O$ is lower than the profit in strategy L. Formally, $\Pi_{M}^{O \bar{D} D}-\Pi_{M}^{L \bar{D} D}=$ $-\left(\left(\left[\delta^{2}-\left(c_{n}+c_{r}+1\right) \quad \delta+2 c_{r}\right]^{2}(4+\delta)\right) /(32(4-\right.$ $\delta)(2-\delta)(1-\delta) \delta))<0$.

(2) The 3PR's profit in strategy $O$ is higher than the profit in strategy L. Formally, $\Pi_{R}^{O D} \bar{D}-\Pi_{R}^{L \bar{D} D}=\left(\left[\delta^{2}-(1+c\right.\right.$ $\left.\left.\left.{ }_{n}+c_{r}\right) \delta+2 c_{r}\right]^{2}\left(\delta^{2}-4 \delta+8\right)\right) /(16(4-$ $\left.\delta)^{2}(2-\delta)(1-\delta) \delta\right)>0$.

(3) The retailer's profit in strategy $O$ is higher than the profit in strategy $L$ if $\delta_{4}<\delta<\delta_{5}$; otherwise, the profit in strategy $O$ is lower than that in strategy $L$. Formally, $\quad \Pi_{T}^{O \bar{D} D}-\Pi_{T}^{L \bar{D} D}=\left[\delta^{2}-\left(1+c_{n}+c_{r}\right) \delta\right.$ $\left.+2 c_{r}\right]\left[32(1-\delta)\left(1-c_{n}\right)+(4-\delta)^{2} c_{r}-(16-\delta)(1-\right.$ $\left.\delta) \delta-\left(7 \delta c_{n}+2 c_{r}\right)\right] \delta /\left(64(4-\delta)^{2}(2-\delta)^{2}(1-\right.$ $\delta))>0$ if $\delta_{4}<\delta<\delta_{5}$ and $\Pi_{T}^{O \bar{D} D}-\Pi_{T}^{L \bar{D} D} \leq 0$ if $\delta \leq \delta_{4}$ or $\delta \geq \delta_{5}$, where $\delta_{4} \in(0,1)$ and $\delta_{5} \in(0,1)$ are defined as the smaller and larger real root of the quintic equation: $\left[\delta^{2}-\left(1+c_{n}+c_{r}\right) \delta+2 c_{r}\right][32(1-\delta)(1-$ $\left.\left.c_{n}\right)+(4-\delta)^{2} c_{r}-(16-\delta)(1-\delta) \delta-\left(7 \delta c_{n}+2 c_{r}\right)\right]$.

According to Proposition 6, we find that, in the structure $\bar{D} D$, the OEM always chooses to license the remanufacturing to the $3 \mathrm{PR}$ in the channel structure $D D$. However, the OEM's choice makes the $3 P R$ get worse (i.e., $\left.\Pi_{R}^{L D D}-\Pi_{R}^{O D D}<0\right)$. And, the retailer also gets worse when the WTP discount factor is in a midrange (i.e., $\Pi_{T}^{L D D}$ $\Pi_{T}^{O D D}<0$ when $\delta_{4}<\delta<\delta_{5}$ ).

4.4. Distribution Channel Structure $\overline{D D}$. In this section, we consider the structure $\overline{D D}$, in which both the new and remanufactured products are sold indirectly. Firstly, consider that the OEM outsources remanufacturing operation. Based on the above model description, we can get the profits of the OEM, the 3PR, and the retailer, which are given by

$$
\begin{aligned}
& \Pi_{M}^{O \overline{D D}}=\left(w_{n}^{O \overline{D D}}-c_{n}\right) d_{n}^{O \overline{D D}}+\left(w_{r}^{O \overline{D D}}-p_{o}^{O \overline{D D}}\right) d_{r}^{O \overline{D D}}, \\
& \Pi_{R}^{O \overline{D D}}=\left(p_{o}^{O \overline{D D}}-c_{r}\right) d_{r}^{O \overline{D D}}, \\
& \Pi_{T}^{O \overline{D D}}=\left(p_{n}^{O \overline{D D}}-w_{n}^{O \overline{D D}}\right) d_{n}^{O \overline{D D}}+\left(p_{r}^{O \overline{D D}}-w_{r}^{O \overline{D D}}\right) d_{r}^{O \overline{D D}} .
\end{aligned}
$$

The sequence of events is as follows: first, the 3PR decides on the outsourcing fee $p_{0}^{O \overline{D D}}$. Secondly, the OEM determines the wholesale price $w_{n}^{O D D}$ of the new products to the retailer and the wholesale price $w_{r}^{O D D}$ of the remanufactured products. Finally, the retailer determines the retail price $p_{n}^{O \overline{D D}}$ and $p_{r}^{O \overline{D D}}$ of the new and remanufactured products, respectively.

Secondly, we consider that the OEM licenses the whole remanufacturing business to the $3 \mathrm{PR}$. In this model, the OEM first decides on the licensing fee $p_{l}^{L \overline{D D}}$. Sequentially, the $3 \mathrm{PR}$ maximizes her profit by optimizing the wholesale price $w_{r}^{L \overline{D D}}$ of the remanufactured products. Simultaneously, the OEM determines the wholesale price $w_{n}^{L \overline{D D}}$ of the new products. Finally, the retailer determines the retail price $p_{n}^{L \overline{D D}}$ and $p_{r}^{L \overline{D D}}$ of the new and remanufactured products, respectively. The profits of the OEM, the $3 \mathrm{PR}$, and the retailer, which are given by

$$
\begin{aligned}
& \Pi_{M}^{L \overline{D D}}=\left(w_{n}^{L \overline{D D}}-c_{n}\right) d_{n}^{L \overline{D D}}+p_{l}^{L \overline{D D}} d_{r}^{L \overline{D D}}, \\
& \Pi_{R}^{L \overline{D D}}=\left(w_{r}^{L \overline{D D}}-c_{r}-p_{l}^{L \overline{D D}}\right) d_{r}^{L \overline{D D}} \\
& \Pi_{T}^{L \overline{D D}}=\left(p_{n}^{L \overline{D D}}-w_{n}^{L \overline{D D}}\right) d_{n}^{L \overline{D D}}+\left(p_{r}^{L \overline{D D}}-w_{r}^{L \overline{D D}}\right) d_{r}^{L \overline{D D}} .
\end{aligned}
$$


Similarly, we use backward induction to ensure subgame perfection. Proposition 7 states the equilibrium solutions in strategy $O$ and strategy $L$.

Proposition 7. In the channel structure $\overline{D D}$, the equilibrium solutions are summarized in Table 5.

We define the unit marginal profits of new products for the OEM as $m p_{n}^{O \overline{D D}}=w_{n}^{O \overline{D D}}-c_{n}$ in strategy $O$ and $m p_{n}^{L \overline{D D}}=$ $w_{n}^{L \overline{D D}}-c_{n}$ in strategy $L$, respectively. The unit marginal profits of remanufactured products for the OEM are $m p_{r}^{O \overline{D D}}=w_{r}^{O \overline{D D}}-p_{o}^{O \overline{D D}}$ in strategy $O$ and $m p_{r}^{L \overline{D D}}=p_{l}^{L \overline{D D}}$ in strategy $L$, respectively. According to Proposition 7, we compare the OEM's equilibrium results, which lead to Corollary 4.

Corollary 4. In the channel structure $\overline{D D}$,

(1) The unit marginal profit of new products for the OEM in strategy $O$ is lower than the profit in strategy $L$. Formally, $\quad m p_{n}^{O \overline{D D}}-m p_{n}^{L D D}=-\left(\left(\delta c_{n}-c_{r}\right)\right.$ $/(8+\delta))<0$.

(2) The unit marginal profit of remanufactured products for the OEM in strategy $O$ is lower than the profit in strategy L. Formally, $m p_{r}^{O \overline{D D}}-m p_{r}^{L \overline{D D}}=-(((8-\delta)$ $\left.\left.\left(\delta c_{n}-c_{r}\right)\right) /(4(8+\delta))\right)<0$.

(3) The demand for new products in strategy $O$ is higher than the demand in strategy. Formally, $d_{n}^{O D D}-$ $d_{n}^{L \overline{D D}}=\left(\left((4-\delta)\left(\delta c_{n}-c_{r}\right)\right) /(8(8+\delta)(1-\delta))\right)>0$.

(4) The demand for remanufactured products in strategy $p_{n}^{O D D} O$ is lower than the demand in strategy $L$. Formally, $\quad d_{r}^{O \overline{D D}}-d_{r}^{L \overline{D D}}=-\left(\left(3\left(\delta c_{n}-c_{r}\right)\right) /\right.$ $(8(8+\delta)(1-\delta)))<0$.

Corollary 4 illustrates that, as the same as the structure $D D$ and $D \bar{D}$, the OEM can get higher unit marginal profits from both new and remanufactured products and a larger demand from remanufactured products in strategy $L$ and structure $\overline{D D}$.

Next, we characterize the conditions for the OEM to choose different remanufacturing strategies in distribution channel structure $\overline{D D}$. By comparing strategy $O$ with strategy $L$, we derive the following proposition.

Proposition 8. In the channel structure $\overline{D D}$,

(1) The OEM's profit in strategy $O$ is lower than the profit in strategy L. Formally, $\Pi_{M}^{O \overline{D D}}-\Pi_{M}^{L \overline{D D}}=$ $-\left(\left((8-\delta)\left(\delta c_{n}-c_{r}\right)^{2}\right) /(32(8+\delta)(1-\delta) \delta)\right)<0$.

(2) The $3 P R$ 's profit in strategy $O$ is higher than the profit in strategy L. Formally, $\Pi_{R}^{O D D}-\Pi_{R}^{L D D}=(((32-16 \delta-$ $\left.\left.\left.7 \delta^{2}\right)\left(\delta c_{n}-c_{r}\right)^{2}\right) /\left(16(8+\delta)^{2}(1-\delta) \delta\right)\right)>0$.

(3) The retailer's profit in strategy $O$ is lower than the profit in strategy $L$ if $\delta>\delta_{6}$; otherwise, the profit in strategy $O$ is higher than that in strategy L. Formally, $\Pi_{T}^{O D D}-\Pi_{T}^{L \overline{D D}}=-\left(\left(\left[\left(16-17 c_{n}\right) \delta^{2}+\left(112-48 c_{n}+\right.\right.\right.\right.$ $\left.\left.c_{r}\right) \delta+128 c_{n}-64 c_{r}-128\right]\left(\delta c_{n}-\right.$

$\left.\left.\left.c_{r}\right)\right) /\left(64(8+\delta)^{2}(1-\delta)\right)\right)<0 \quad$ if $\quad \delta>\delta_{6} \quad$ and
$\Pi_{T}^{O \overline{D D}}-\Pi_{T}^{L \overline{D D}} \geq 0$ if $\delta \leq \delta_{6}$, where $\delta_{6} \in(0,1)$ is defined as the real root of the quadratic equation: (16$\left.17 c_{n}\right) \delta^{2}+\left(112-48 c_{n}+c_{r}\right) \delta+128 c_{n}-64 c_{r}-128$.

Proposition 8 demonstrates that when both new and remanufactured products are sold through the retailer, the OEM licenses the whole remanufacturing business to the 3PR no matter what the WTP discount factor is. Compared with strategy $O$, the 3 PR realizes a lower profit in strategy $L$. The sign of the retailer's profit change depends on the WTP discount factor. Specifically, with a high WTP discount factor, the retailer gets better (i.e., $\Pi_{T}^{L \overline{D D}}-\Pi_{T}^{O \overline{D D}}>0$ when $\delta>\delta_{6}$ ) and the retailer gets worse with a low WTP discount factor (i.e., $\Pi_{T}^{L \overline{D D}}-\Pi_{T}^{O D D} \leq 0$ when $\delta \leq \delta_{6}$ ).

4.5. Consumer Surplus, Social Welfare, and Environmental Impact. In this section, we extend the analysis from pure profit orientation to include a consumer surplus perspective, a social welfare perspective, and an environmental impact perspective.

For the consumer of type $\theta$, the surplus of an individual consumer who purchases a new product is $\theta-p_{n}^{j s}$ and the surplus of an individual consumer who purchases a remanufactured product is $\delta \theta-p_{r}^{j s}$. Therefore, the total consumer surplus is given by

$$
\mathrm{CS}^{j s}=\int_{1-d_{n}^{j s}-d_{r}^{j s}}^{1-d_{n}^{j s}}\left(\delta \theta-p_{r}^{j s}\right) \mathrm{d} \theta+\int_{1-d_{n}^{j s}}^{1}\left(\theta-p_{n}^{j s}\right) \mathrm{d} \theta .
$$

Correspondingly, the social welfare in strategy $j$ and channel structure $s$ is given by

$$
\mathrm{SW}^{j s}=\mathrm{CS}^{j s}+\Pi_{M}^{j s}+\Pi_{R}^{j s}+\Pi_{T}^{j s} .
$$

From the environmental impact perspective, when the OEM produces $d_{n}^{j s}$ units and the 3PR remanufactures $d_{r}^{j s}$ units, the total environmental impact in strategy $j$ and channel structure $s$ is given by

$$
\mathrm{EI}^{j s}=d_{n}^{j s} e_{n}+d_{r}^{j s} e_{r} .
$$

The next lemma shows the consumer surplus, social welfare, and environmental impact in different strategies and channel structures.

Lemma 1. In the strategy $j$ and channel structure $s$, the consumer surplus, social welfare, and environmental impact are summarized in Tables 6-8, respectively.

Proposition 9 demonstrates the important relationships we derive from Lemma 1.

\section{Proposition 9}

(1) In the channel structure DD, the consumer surplus in strategy $O$ is higher than that in strategy $L$ if $\delta<\delta_{6}$ and is lower than that in strategy $L$ if $\delta \geq \delta_{6}$; the social welfare in strategy $O$ is higher than that in strategy $L$ if $\delta<\delta_{7}$ and is lower than that in strategy $L$ if $\delta \geq \delta_{7}$; the environmental impact in strategy $O$ is higher than that in strategy L. Formally, $C S^{O D D}-C S^{L D D}$ 


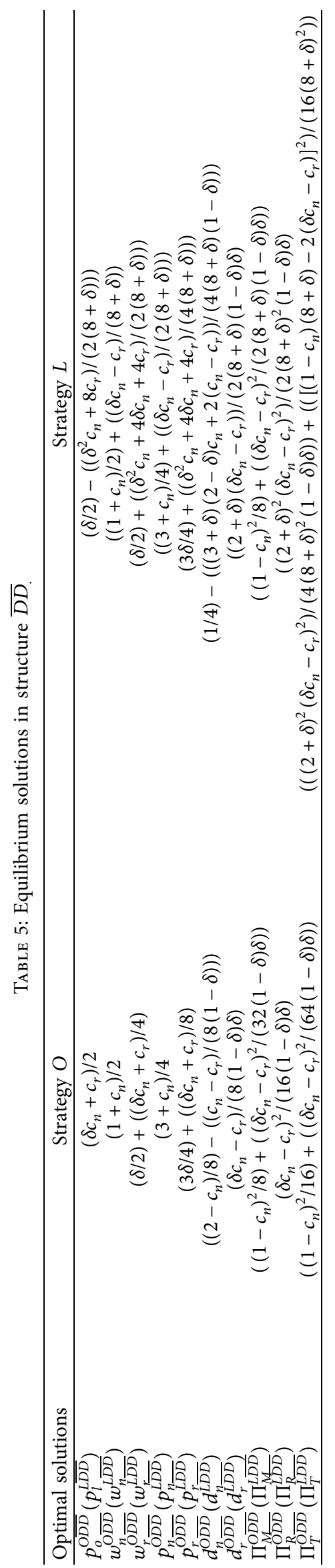




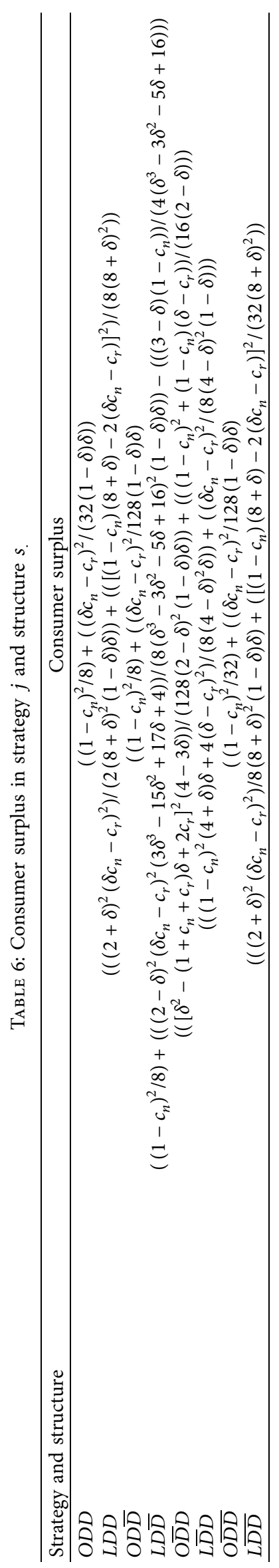




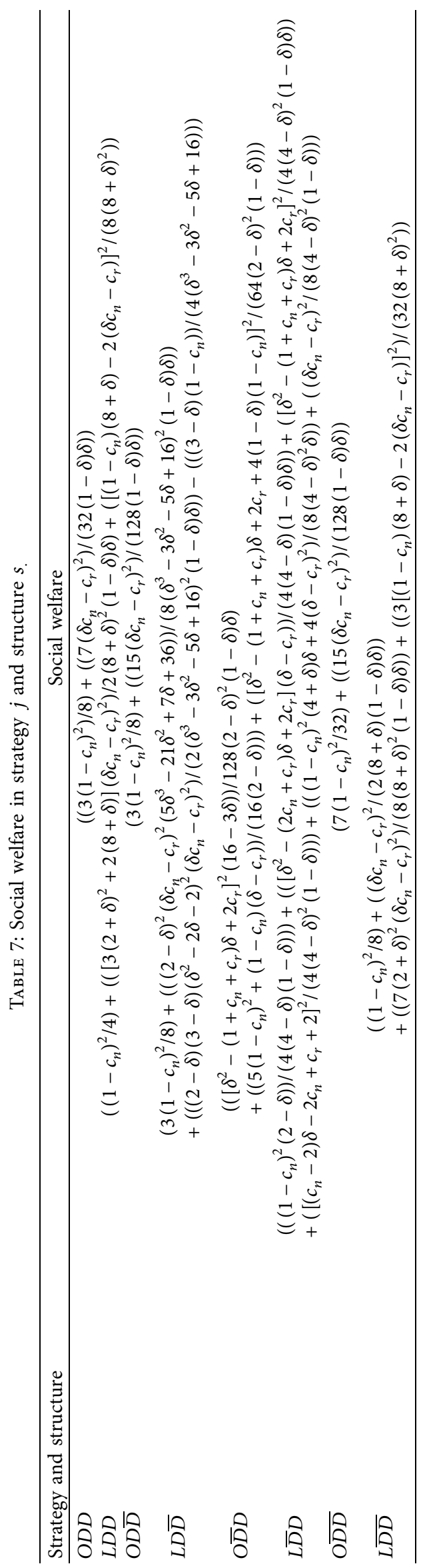


TABle 8: Environmental impact in strategy $j$ and structure $s$.

\begin{tabular}{lc}
\hline Strategy and structure & Environmental impact \\
\hline$O D D$ & $\left(\left(\left(2-c_{n}\right) e_{n}\right) / 4\right)+\left(\left(\left(\delta c_{n}-c_{r}\right)\left(e_{r}-\delta e_{n}\right)\right) /(4(1-\delta) \delta)\right)$ \\
$L D D$ & $\left(e_{n} / 2\right)+\left(\left(\left(\delta^{2} c_{n}+\delta c_{n}-8 c_{n}+6 c_{r}\right) e_{n}\right) /(2(1-\delta)(8+\delta))\right)+\left(\left((2+\delta)\left(\delta c_{n}-c_{r}\right) e_{r}\right) /((8+\delta)(1-\delta) \delta)\right)$ \\
$O D \bar{D}$ & $\left(\left(\left(1-c_{n}\right) e_{n}\right) / 2\right)+\left(\left(\left(\delta c_{n}-c_{r}\right)\left(e_{r}-\delta e_{n}\right)\right) /(8(1-\delta) \delta)\right)$ \\
$L \bar{D} \bar{D}$ & $\left(\left(\left(1-c_{n}\right) e_{n}\right) / 2\right)-\left(\left((2-\delta)(5-2 \delta)\left(\delta c_{n}-c_{r}\right) e_{n}\right) /\left(2\left(\delta^{3}-3 \delta^{2}-5 \delta+16\right)(1-\delta)\right)\right)$ \\
$O \bar{D} D$ & $+\left(\left((2-\delta)\left(2-\delta^{2}+2 \delta\right)\left(\delta c_{n}-c_{r}\right) e_{r}\right) /\left(2\left(\delta^{3}-3 \delta^{2}-5 \delta+16\right)(1-\delta) \delta\right)\right)$ \\
$L \bar{D} D$ & $\left(e_{n} / 8\right)+\left(\left(\left(1-2 c_{n}\right) e_{n}\right) /(4(2-\delta))\right)+\left(\left(\left(\delta-c_{r}\right) e_{r}\right) / 8 \delta\right)+\left(\left(\left(\delta c_{n}-c_{r}\right)\left(e_{r}-\delta e_{n}\right)\right) /(8(1-\delta) \delta)\right)$ \\
$O \overline{D D}$ & $\left(\left(\left[\left(c_{n}-2\right) \delta-2 c_{n}+c_{r}+2\right] e_{n}\right) /(2(4-\delta)(1-\delta))\right)$ \\
$L \overline{D D}$ & $+\left(\left(\left[\left(1+c_{n}+c_{r}\right) \delta-\delta^{2}-2 c_{r}\right] e_{r}\right) /(2(4-\delta)(1-\delta))\right)$ \\
\hline & $\left.\left(\left(2-c_{n}\right) e_{n}\right) / 8\right)+\left(\left(\left(\delta c_{n}-c_{r}\right)\left(e_{r}-\delta e_{n}\right)\right) /(8(1-\delta) \delta)\right)$ \\
\end{tabular}

$=\left(\left(\left[\left(17 c_{n}-16\right) \delta^{2}+\left(48 c_{n}-c_{r}-112\right) \delta-128 c_{n}+\right.\right.\right.$ $\left.\left.\left.64 c_{r}+128\right]\left(\delta c_{n}-c_{r}\right)\right) /\left(32(8+\delta)^{2}(1-\delta)\right)\right)>0 \quad$ if $\delta<\delta_{6}$ and $C S^{O D D}-C S^{L D D} \leq 0$ if $\delta \geq \delta_{6}$, where $\delta_{6} \in(0,1)$ is defined as the real root of the quadratic equation: $\quad\left(16-17 c_{n}\right) \delta^{2}+\left(112-48 c_{n}+\right.$ $\left.c_{r}\right) \delta+128 c_{n}-64 \quad c_{r}-128 . \quad S W^{O D D}-S W^{L D D}=$ $\left(\left(\left[\left(9 c_{n}+16\right) \delta^{2}+\left(16 c_{n}-25 c_{r}+112\right) \delta+128\left(c_{n}-\right.\right.\right.\right.$ $\left.\left.\left.\left.c_{r}-1\right)\right]\left(\delta c_{n}-c_{r}\right)\right) /\left(32(8+\delta)^{2}(\delta-1)\right)\right)>0$ if $\delta<\delta_{7}$ and $S W^{O D D}-S W^{L D D} \leq 0$ if $\delta \geq \delta_{7}$, where $\delta_{7} \in(0,1)$ is defined as the real root of the quadratic equation: $\left(9 c_{n}+16\right) \delta^{2}+\left(16 c_{n}-25 c_{r}-112\right)$

$$
\begin{aligned}
& \delta+128 c_{n}-128 c_{r}-128 . \\
& E I^{O D D}-E I^{L D D}=\left(\left(\left[(4-\delta) e_{n}-3\right.\right.\right. \\
& \left.\left.\left.e_{r}\right]\left(\delta c_{n}-c_{r}\right)\right) /(4(8+\delta)(1-\delta))\right)>0 .
\end{aligned}
$$

(2) In the channel structure $D \bar{D}$, the consumer surplus in strategy $O$ is higher than that in strategy $L$ if $\delta<\delta_{8}$ and is lower than that in strategy $L$ if $\delta \geq \delta_{8}$; the social welfare in strategy $O$ is higher than that in strategy $L$ if $\delta<\delta_{9}$ and is lower than that in strategy L if $\delta \geq \delta_{9}$; the environmental impact in strategy $O$ is higher than that in strategy L. Formally,

$\mathrm{CS}^{O D \bar{D}}-\mathrm{CS}^{L D \bar{D}}=\frac{\left[\left(33 c_{n}-32\right) \delta^{6}+\left(288-342 c_{n}-c_{r}\right) \delta^{5}+\left(1199 c_{n}+54 c_{r}-768\right) \delta^{4}-\left(1138 c_{n}+431 c_{r}-224\right) \delta^{3}-\left(2343 c_{n}-1362 c_{r}-4256\right) \delta^{2}+\left(5600 c_{n}-1913 c_{r}-6592\right) \delta-3072 c_{n}+992 c_{r}+3072\right]\left(\delta c_{n}-c_{r}\right)}{\left(128\left(\delta^{3}-3 \delta^{2}-5 \delta+16\right)^{2}(1-\delta)\right)}>0$

if $\delta<\delta_{8}$ and $C S^{O D \bar{D}}-C S^{L D \bar{D}} \leq 0$ if $\delta \geq \delta_{8}$, where $\delta_{8} \in(0,1)$ is defined as the real root of the sixth degree equation: $\quad\left(33 c_{n}-32\right) \delta^{6}+(288-342 c$

$$
\begin{aligned}
& \left.n-c_{r}\right) \delta^{5}+\left(1199 c_{n}+54 c_{r}-768\right) \delta^{4}-\left(1138 c_{n}+431 c_{r}\right. \\
& -224) \delta^{3}-\left(2343 c_{n}-1362 c_{r}-4256\right) \delta^{2} \\
& +\left(5600 c_{n}-1913 c_{r}-6592\right) \delta-3072 c_{n}+992 c_{r}+3072
\end{aligned}
$$

$\mathrm{SW}^{\mathrm{OD} \bar{D}}-\mathrm{SW}^{L D \bar{D}}=\frac{\left[\left(17 c_{n}+32\right) \delta^{6}-\left(118 c_{n}+49 c_{r}+288\right) \delta^{5}+\left(255 c_{n}+406 c_{r}+768\right) \delta^{4}-\left(402 c_{n}+1023 c_{r}-224\right) \delta^{3}+\left(1801 c_{n}+178 c_{r}-4256\right) \delta^{2}-\left(4256 c_{n}-2455 c_{r}-6592\right) \delta+3072\left(c_{n}-1\right)-2336 c_{r}\right]\left(\delta c_{n}-c_{r}\right)}{128\left(\delta^{3}-3 \delta^{2}-5 \delta+16\right)^{2}(\delta-1)}>0$

if $\delta<\delta_{9}$ and $S W^{O D \bar{D}}-S W^{L D \bar{D}} \leq 0$ if $\delta \geq \delta_{9}$, where $\delta_{9} \in(0,1)$ is defined as the real root of the sixth degree equation:

$\left(17 c_{n}+32\right) \delta^{6}-\left(118 c_{n}+49 c_{r}+288\right) \delta^{5}+\left(255 c_{n}+\right.$ $\left.406 c_{r}+768\right) \quad \delta^{4}-\left(402 c_{n}+1023 c_{r}-224\right) \delta^{3}+$ $\left(1801 c_{n}+178 c_{r}-4256\right) \delta^{2}-$

$\left(4256 c_{n}-2455 c_{r}-6592\right) \delta+3072\left(c_{n}-1\right)-2336 c_{r}$ :

$$
\mathrm{EI}^{\mathrm{OD} \bar{D}}-\mathrm{EI}^{L D \bar{D}}=\frac{\left[-e_{n} \delta^{3}+\left(11 e_{n}-3 e_{r}\right) \delta^{2}-\left(31 e_{n}+13 e_{r}\right) \delta+24 e_{n}-13 e_{r}\right]\left(\delta c_{n}-c_{r}\right)}{8\left(\delta^{3}-3 \delta^{2}-5 \delta+16\right)(1-\delta)}>0 .
$$

(3) In the channel structure $\bar{D} D$, the consumer surplus in strategy $O$ is higher than that in strategy $L$; the social welfare in strategy $O$ is higher than that in strategy; the environmental impact in strategy $\mathrm{O}$ is higher than that in strategy $L$ if $\delta>\left(2 e_{r} /\left(e_{n}+e_{r}\right)\right)$ and is lower than that in strategy $L$ if $\delta \leq\left(2 e_{r} /\left(e_{n}+e_{r}\right)\right)$. Formally, 


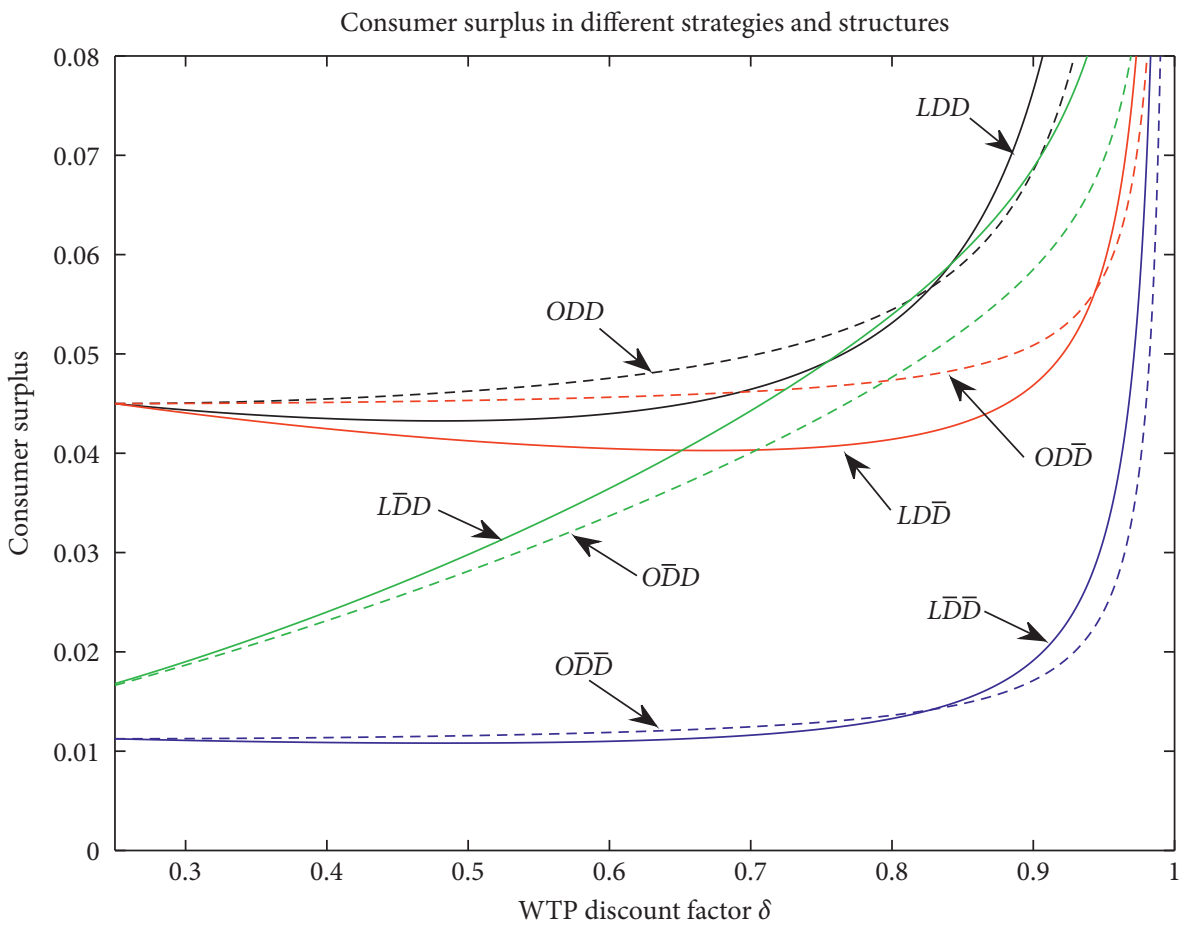

FIgURE 2: Consumer surplus in different strategies and distribution channel structures.

$$
\begin{aligned}
\mathrm{CS}^{O \bar{D} D}-\mathrm{CS}^{L \bar{D} D} & =\frac{\left[\delta^{2}-\left(1+c_{n}+c_{r}\right) \delta+2 c_{r}\right]\left[3 \delta^{4}+\left(5 c_{n}-3 c_{r}-39\right) \delta^{3}-\left(12 c_{n}-34 c_{r}-100\right) \delta^{2}-\left(88 c_{r}+64\right) \delta+64 c_{r}\right]}{128(4-\delta)^{2}(2-\delta)^{2}(\delta-1)}>0, \\
\mathrm{SW}^{O \bar{D} D}-\mathrm{SW}^{L \bar{D} D} & =\frac{\left[\delta^{2}-\left(1+c_{n}+c_{r}\right) \delta+2 c_{r}\right]\left[13 \delta^{4}-\left(21 c_{n}+13 c_{r}+73\right) \delta^{3}+\left(108 c_{n}+94 c_{r}+124\right) \delta^{2}-\left(128 c_{n}+232 c_{r}+64\right) \delta+192 c_{r}\right]}{128(4-\delta)^{2}(2-\delta)^{2}(\delta-1)}>0, \\
\mathrm{EI}^{O \bar{D} D}-\mathrm{EI}^{L \bar{D} D} & =\frac{\left[\left(e_{n}+e_{r}\right) \delta-2 e_{r}\right]\left[\delta^{2}-\left(1+c_{n}+c_{r}\right) \delta+2 c_{r}\right]}{8(4-\delta)(2-\delta)(\delta-1)}>0,
\end{aligned}
$$

if $\delta>\left(2 e_{r} /\left(e_{n}+e_{r}\right)\right)$ and $E I^{O \bar{D} D}-E I^{L \bar{D} D} \leq 0$ if $\delta \leq\left(2 e_{r} /\left(e_{n}+e_{r}\right)\right)$.

(4) In the channel structure $\overline{D D}$, the consumer surplus in strategy $O$ is higher than that in strategy $L$ if $\delta<\delta_{6}$ and is lower than that in strategy $L$ if $\delta \geq \delta_{6}$; the social welfare in strategy $O$ is higher than that in strategy $L$ if $\delta<\delta_{10}$ and is lower than that in strategy $L$ if $\delta \geq \delta_{10}$; the environmental impact in strategy $O$ is higher than that in strategy L. Formally,

$$
\mathrm{CS}^{O \overline{D D}}-\mathrm{CS}^{L \overline{D D}}=\frac{\left[\left(17 c_{n}-16\right) \delta^{2}+\left(48 c_{n}-c_{r}-112\right) \delta-128 c_{n}+64 c_{r}+128\right]\left(\delta c_{n}-c_{r}\right)}{128(8+\delta)^{2}(1-\delta)}>0,
$$

if $\delta<\delta_{6}$ and $C S^{O \overline{D D}}-C S^{L \overline{D D}} \leq 0$ if $\delta \geq \delta_{6}$, where $\delta_{6} \in(0,1)$ is defined as the real root of the quadratic equation: $\quad\left(16-17 c_{n}\right) \delta^{2}+\left(112-48 c_{n}+c_{r}\right)$ $\delta+128 c_{n}-64 c_{r}-128:$

$$
\mathrm{SW}^{\mathrm{ODD}}-\mathrm{SW}^{L \overline{D D}}=\frac{\left[\left(c_{n}+48\right) \delta^{2}-\left(16 c_{n}+49 c_{r}+336\right) \delta+384\left(c_{n}-1\right)--320 c_{r}\right]\left(\delta c_{n}-c_{r}\right)}{128(8+\delta)^{2}(\delta-1)}>0
$$




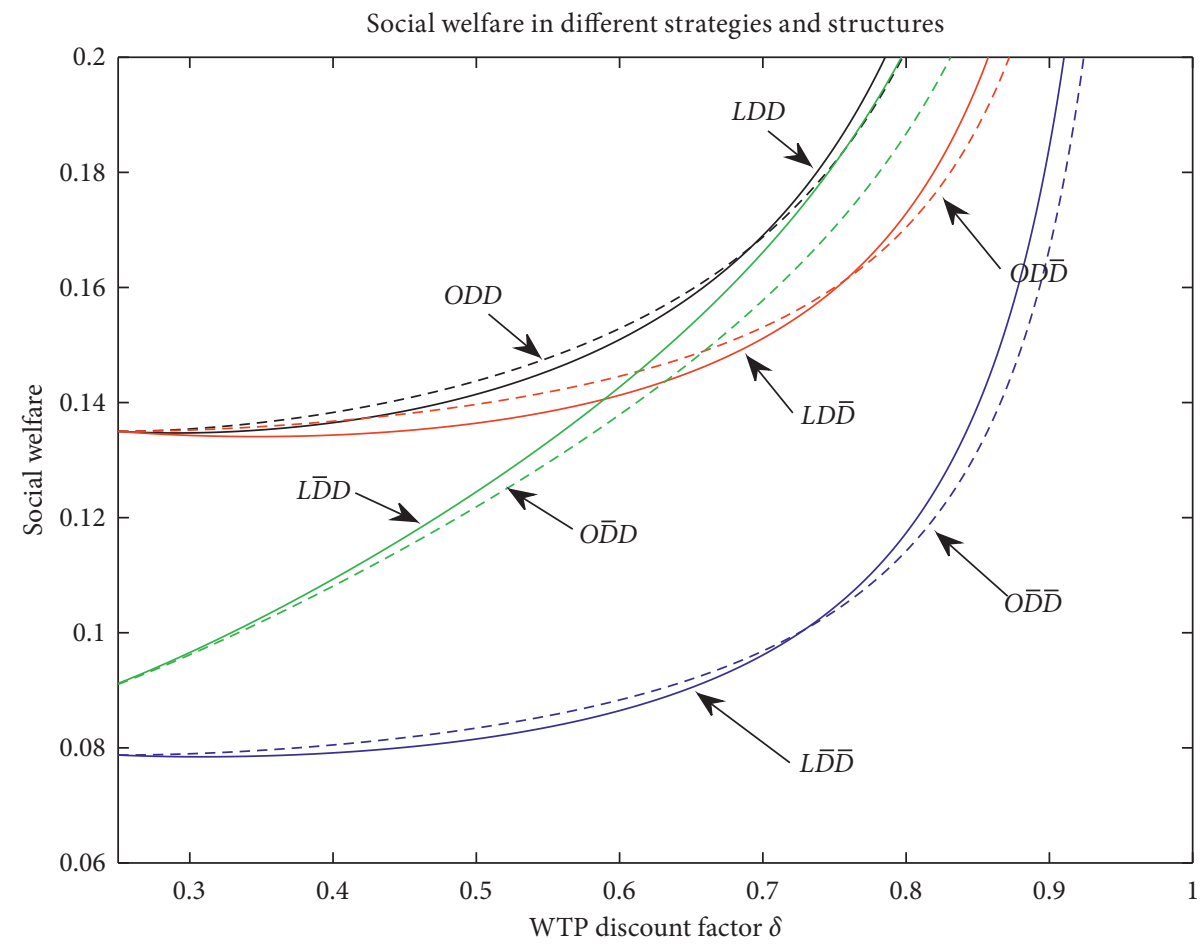

FIGURE 3: Social welfare in different strategies and distribution channel structures.

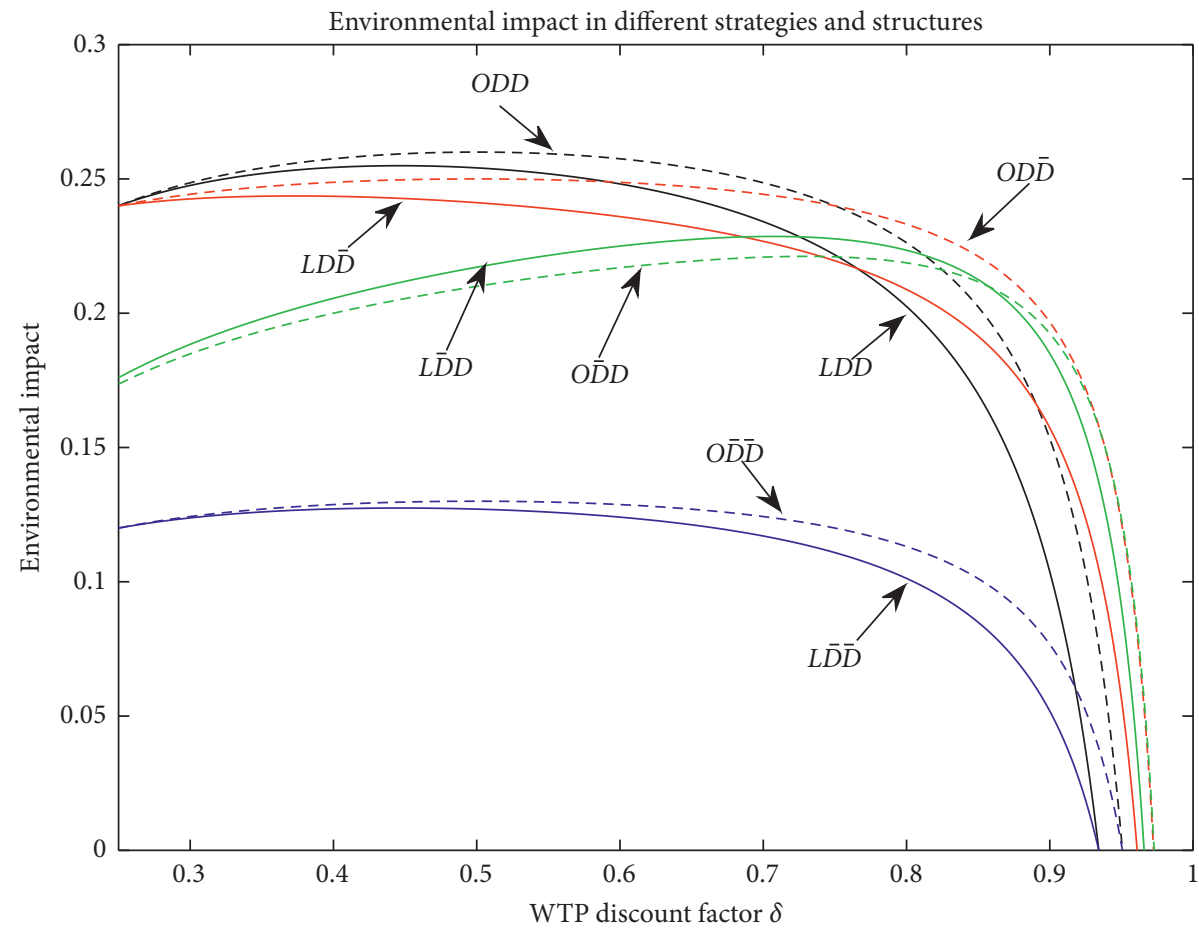

FIGURE 4: Environmental impact in different strategies and distribution channel structures.

if $\delta<\delta_{10}$ and $S W^{O \overline{D D}}-S W^{L \overline{D D}} \leq 0$ if $\delta \geq \delta_{10}$, where $\delta_{10} \in(0,1)$ is defined as the real root of the quadratic equation: $\quad\left(c_{n}+48\right) \delta^{2}-\left(16 c_{n}+49 c_{r}+336\right) \delta+$ $384 c_{n}-320 c_{r}-384:$
$\mathrm{EI}^{\mathrm{ODD}}-\mathrm{EI}^{L D D}=\frac{\left[(4-\delta) e_{n}-3 e_{r}\right]\left(\delta c_{n}-c_{r}\right)}{8(8+\delta)(1-\delta)}>0$. 
Proposition 9 illustrates that, in the different channel structures, the optimal remanufacturing strategy may lead to higher or lower consumer surplus, social welfare, and environmental impact. More precisely, in the channel structure $D D$ and $\overline{D D}$, the OEM's remanufacturing strategy benefits consumers and society when the WTP discount factor is sufficiently high and hurts them when the factor is sufficiently low. In the channel structure $D \bar{D}$, the OEM's remanufacturing strategy benefits consumers and society when the WTP discount factor is either low or high and hurts them otherwise. In the channel structure $\bar{D} D$, the OEM's remanufacturing strategy always benefits consumers and society. We present Figures 2 and 3 to provide a visual illustration of consumer surplus and social welfare in different strategies and structures, respectively.

Notes. The following parameter values are used: $c_{n}=0.4$ and $c_{r}=0.1$. Qualitatively, the results do not change for other values of the parameter.

Notes. The following parameter values are used: $c_{n}=0.4$ and $c_{r}=0.1$. Qualitatively, the results do not change for other values of the parameter.

In terms of environmental impact, we present Figure 4 to clarify.

Notes. The following parameter values are used: $c_{n}=0.4$, $c_{r}=0.1, e_{n}=0.8$, and $e_{r}=0.6$. Qualitatively, the results do not change for other values of the parameter.

In the channel structure $D D$ and $\overline{D D}$, the OEM's remanufacturing strategy is always friendly to the environment. However, in the channel structure $D \bar{D}$ and $\bar{D} D$, the strategy is environmentally friendly when the WTP discount factor is high and unfriendly to the environment when the factor is low.

\section{Conclusions}

In this study, we seek insights for OEMs that consider cooperating with 3PRs. Inspired by some examples found in practice, we consider the interaction among three firms, including an OEM who produces a new remanufactured product and has two remanufacturing strategies (i.e., outsourcing and licensing), a 3PR who collects and remanufactures the returned products, and a retailer through which the OEM and 3PR sell their products. Given this construct, we derive the optimal product pricing and resulting product sales and profits of different entities in different remanufacturing strategies and channel structures. To the best of our knowledge, this study is the first to shed light on the remanufacturing strategy in the channel structure. We demonstrate that outsourcing remanufacturing benefits the OEM when the new products are sold directly and remanufactured products, with a relatively low valuation, are sold indirectly; otherwise, licensing remanufacturing is more beneficial for the OEM. In line with our findings, Panasonic sells its remanufactured products, which with relatively low valuations, through several reseller partners, including Bizco, BAYCOM, and Daly Computers, Dell licenses its remanufacturing operations and sales to GENCO ATC, and Apple licenses its remanufacturing business in China to Foxconn.

In addition, we have come to several interesting results. First, we find that, in the channel structure $D D$, the OEM always chooses to license the remanufacturing to the $3 \mathrm{PR}$ and such a choice makes the 3PR get worse. Second, in the channel structure $D \bar{D}$, the OEM prefers to license the remanufacturing when the consumers perceive the remanufactured products with a high value (i.e., the WTP discount factor is sufficiently high); otherwise, outsourcing remanufacturing is more beneficial for the OEM. According to the OEM's selection, the 3PR realizes a higher profit when the discount factor is high or low and the retailer realizes a higher profit when the discount factor is high. Third, in the channel structure $\bar{D} D$, the OEM prefers licensing remanufacturing whereas the $3 \mathrm{PR}$ prefers outsourcing remanufacturing and the retailer prefers licensing remanufacturing with a high or low discount factor. Fourth, in the channel structure $\overline{D D}$, the OEM also prefers to license the remanufacturing to the $3 \mathrm{PR}$, and such strategy selection hurts the $3 P R$ and the retailer when consumers perceive remanufactured products with a low value. Fifth, from the perspective of consumer surplus and social welfare, the OEM's strategy selection benefits consumers and society when the WTP discount factor is high and regardless of the channel structure. The selection also benefits them when the discount factor is low and in the channel structure $D \bar{D}$. Finally, the OEM's remanufacturing strategies are always environmentally friendly in the channel structure $D D$ and $\overline{D D}$. In the structure $D \bar{D}$ and $\bar{D} D$, the strategies benefit the environment when consumers perceive remanufactured products with a high value.

Our work also has some limitations. We consider the channel structures are exogenous. Relaxing this assumption and considering the OEM not only selects the remanufacturing strategies but also selects the distribution channel structures which may derive more insights. Furthermore, it would be interesting to study how the OEM could outsource or license remanufacturing operations to the retailer.

\section{Appendix}

\section{A. Proof of Propositions}

Proof of Proposition 1. In the channel structure $D D$ and strategy $O$, the $3 P R$ first decides $p_{o}^{O D D}$ and then the OEM decides $p_{n}^{O D D}$ and $p_{r}^{O D D}$.

Given the outsourcing fee $p_{o}^{O D D}$, the OEM solves the following problem to maximize his profit:

$$
\Pi_{M}^{O D D}=\left(p_{n}^{O D D}-c_{n}\right) d_{n}^{O D D}+\left(p_{r}^{O D D}-p_{o}^{O D D}\right) d_{r}^{O D D},
$$

which yields $p_{r}^{O D D}=\left(\left(\left(2 p_{n}^{O D D}-c_{n}\right) \delta+p_{o}^{O D D}\right) / 2\right)$ and $p_{n}^{O D D}=\left(\left(1-\delta+2 p_{r}^{O D D}+c_{n}-p_{o}^{O D D}\right) / 2\right)$. Solving $p_{n}^{O D D}$ and $p_{r}^{O D D}$ simultaneously yields 


$$
\begin{aligned}
& p_{n}^{O D D}=\frac{1+c_{n}}{2}, \\
& p_{r}^{O D D}=\frac{\delta+p_{o}^{O D D}}{2} .
\end{aligned}
$$

Substituting them into the 3PR's profit function and then solving for optimality with respect to $p_{o}^{O D D}$, we can obtain the optimal outsourcing fee:

$$
p_{o}^{O D D}=\frac{\delta c_{n}+c_{r}}{2}
$$

By bringing this back to the equations of prices, demands, and profits, we can derive the optimums.

In the channel structure $D D$ and strategy $L$, the OEM first decides $p_{l}^{L D D}$, then the 3PR decides $p_{r}^{O D D}$, and the OEM decides $p_{n}^{O D D}$.

Given the licensing fee $p_{l}^{L D D}$, the OEM solves the following problem to maximize his profit:

$$
\Pi_{M}^{L D D}=\left(p_{n}^{L D D}-c_{n}\right) d_{n}^{L D D}+p_{l}^{L D D} d_{r}^{L D D},
$$

which yields $p_{n}^{L D D}=\left(\left(1-\delta+p_{r}^{L D D}+c_{n}+p_{l}^{L D D}\right) / 2\right)$. The $3 P R$ 's optimal retail price of remanufactured products is given by solving

$$
\Pi_{R}^{L D D}=\left(p_{r}^{L D D}-c_{r}-p_{l}^{L D D}\right) d_{r}^{L D D},
$$

which yields $p_{r}^{L D D}=\left(\left(\delta p_{n}^{L D D}+c_{r}+p_{l}^{L D D}\right) / 2\right)$. Solving $p_{n}^{L D D}$ and $p_{r}^{L D D}$ simultaneously yields

$$
\begin{aligned}
p_{n}^{L D D} & =\frac{2\left(1-\delta+c_{n}\right)+c_{r}-3 p_{l}^{L D D}}{4-\delta}, \\
p_{r}^{L D D} & =\frac{\left(1+c_{n}+p_{l}^{L D D}\right) \delta+2 c_{r}+2 p_{l}^{L D D}-\delta^{2}}{4-\delta} .
\end{aligned}
$$

Substituting them into the OEM's profit function and then solving for optimality with respect to $p_{l}^{L D D}$, we can obtain the optimal licensing fee:

$$
p_{l}^{L D D}=\frac{\delta^{2}\left(1-c_{n}\right)+8\left(\delta-c_{r}\right)}{2(8+\delta)} .
$$

By bringing this back to the equations of prices, demands, and profits, we can derive the optimums.

Proof of Corollary 1. This corollary is easily proved by comparing the optimal solutions in Proposition 1, so we omit it.

Proof of Proposition 2. This process of proof is akin to Corollary 1 , and it is easily proved.

Proof of Proposition 3. In the channel structure $D \bar{D}$ and strategy $O$, the $3 P R$ first decides $p_{o}^{O D \bar{D}}$ and then the OEM decides $p_{n}^{O D \bar{D}}$ and $w_{r}^{O D \bar{D}}$. Finally, the retailer decides $p_{r}^{O D \bar{D}}$.

Given the outsourcing fee $p_{o}^{O D \bar{D}}$, retail price $p_{n}^{O D \bar{D}}$, and wholesale price $w_{r}^{O D \bar{D}}$, the retailer solves the following problem to maximize its profit:

$$
\Pi_{T}^{O D \bar{D}}=\left(p_{r}^{O D \bar{D}}-w_{r}^{O D \bar{D}}\right) d_{r}^{O D \bar{D}}
$$

which yields $p_{r}^{O D \bar{D}}=\left(\left(\delta p_{n}^{O D \bar{D}}+w_{r}^{O D \bar{D}}\right) / 2\right)$. Substituting it into the OEM's profit function and then solving for optimality with respect to $p_{n}^{O D \bar{D}}$ and $w_{r}^{O D \bar{D}}$, we can obtain

$$
\begin{aligned}
& p_{n}^{O D \bar{D}}=\frac{(2-\delta) c_{n}+2\left(1-\delta+w_{r}^{O D \bar{D}}\right)-p_{o}^{O D \bar{D}}}{2(2-\delta)}, \\
& w_{r}^{O D \bar{D}}=\frac{\left(2 p_{n}^{O D \bar{D}}-c_{n}\right) \delta+p_{o}^{O D \bar{D}}}{2} .
\end{aligned}
$$

Substituting them into the 3PR's profit function and then solving for optimality with respect to $p_{o}^{O D \bar{D}}$, we can obtain the optimal outsourcing fee:

$$
p_{o}^{O D \bar{D}}=\frac{\delta c_{n}+c_{r}}{2} .
$$

By bringing this back to the equations of prices, demands, and profits, we can derive the optimums.

In the channel structure $D \bar{D}$ and strategy $L$, the OEM first decides $p_{l}^{L D \bar{D}}$ and then the 3PR decides $w_{r}^{L D} \bar{D}$. Finally, the OEM decides $p_{n}^{L D \bar{D}}$ and the retailer decides $p_{r}^{L D} \bar{D}$.

Given $p_{l}^{L D \bar{D}}$ and $w_{r}^{L D \bar{D}}$, the retailer solves the following problem to maximize its profit:

$$
\Pi_{T}^{L D \bar{D}}=\left(p_{r}^{L D \bar{D}}-w_{r}^{L D \bar{D}}\right) d_{r}^{L D \bar{D}},
$$

which yields $p_{r}^{L D \bar{D}}=\left(\left(\delta p_{n}^{L D \bar{D}}+w_{r}^{L D \bar{D}}\right) / 2\right)$. The OEM's optimal retail price of new products is given by solving

$$
\Pi_{M}^{L D \bar{D}}=\left(p_{n}^{L D \bar{D}}-c_{n}\right) d_{n}^{L D \bar{D}}+p_{l}^{L D \bar{D}} d_{r}^{L D \bar{D}},
$$

which yields $p_{n}^{L D \bar{D}}=\left(\left(1-\delta+p_{r}^{L D \bar{D}}+c_{n}+p_{l}^{L D \bar{D}}\right) / 2\right)$. Solving $p_{n}^{L D \bar{D}}$ and $p_{r}^{L D \bar{D}}$ simultaneously yields

$$
\begin{aligned}
& p_{n}^{L D \bar{D}}=\frac{2\left(1-\delta+c_{n}+p_{l}^{L D \bar{D}}\right)+w_{r}^{L D \bar{D}}}{4-\delta}, \\
& p_{r}^{L D \bar{D}}=\frac{\left(1+c_{n}+p_{l}^{L D \bar{D}}\right) \delta+2 w_{r}^{L D \bar{D}}-\delta^{2}}{4-\delta} .
\end{aligned}
$$

Substituting them into the 3PR's profit function and then solving for optimality with respect to $w_{r}^{L D \bar{D}}$, we can obtain the optimal wholesale price:

$$
w_{r}^{L D \bar{D}}=\frac{\left(1+c_{n}-c_{r}\right) \delta+2 c_{r}+2 p_{l}^{L D \bar{D}}-\delta^{2}}{2(2-\delta)} .
$$

Substituting them into the OEM's profit function and then solving for optimality with respect to $p_{l}^{L D \bar{D}}$, we can obtain the optimal licensing fee:

$$
p_{l}^{L D \bar{D}}=\frac{\delta\left(1-c_{n}\right)}{2}+\frac{(2-\delta)(8-3 \delta)\left(\delta c_{n}-c_{r}\right)}{2\left(\delta^{3}-3 \delta^{2}-5 \delta+16\right)} .
$$

By bringing this back to the equations of prices, demands, and profits, we can derive the optimums. 
Proof of Corollary 2. This corollary is easily proved by comparing the optimal solutions in Proposition 3, so we omit it.

Proof of Proposition 4. This process of proof is akin to Corollary 2 , and it is easily proved.

Proof of Proposition 5. This process of proof is akin to Proposition 3, and it is easily proved.

Proof of Corollary 3. This corollary is easily proved by comparing the optimal solutions in Proposition 5, so we omit it.

Proof of Proposition 6. This process of proof is akin to Corollary 3 , and it is easily proved.

Proof of Proposition 7. This process of proof is akin to Proposition 3, and it is easily proved.

Proof of Corollary 4. This corollary is easily proved by comparing the optimal solutions in Proposition 7, so we omit it.

Proof of Proposition 8. This process of proof is akin to Corollary 4 , and it is easily proved.

Proof of Lemma 1. Substituting the optimal solutions in Propositions 1, 3, 5, and 7 into equations (9)-(11), we can get the consumer surplus, social welfare, and environmental impact in different channel structures and remanufacturing strategies, respectively.

Proof of Proposition 9. This proposition is easily proved by comparing the consumer surplus, social welfare, and environmental impact in Lemma 1, so we omit it.

\section{Conflicts of Interest}

The authors declare that they have no conflicts of interest.

\section{Authors' Contributions}

X. W. proposed the main idea, constructed the model, and analyzed the model. Y. W. wrote the manuscript. All authors have read and agreed to the published version of the manuscript.

\section{References}

[1] What is Remanufacturing? http://www.remancouncil.org/ educate/remanufacturing-information/what-isremanufacturing (2020).

[2] America's Remanufacturing Company Celebrates Global Remanufacturing Day 2019. http://www.digitaljournal.com/ pr/4265355.

[3] The Rise of Remanufacturing. https://industrytoday.com/therise-of-remanufacturing/(2020).

[4] Z.-B. Zou, J.-J. Wang, G.-S. Deng, and H. Chen, "Third-party remanufacturing mode selection: outsourcing or authorization?" Transportation Research Part E: Logistics and Transportation Review, vol. 87, pp. 1-19, 2016.

[5] J. D. Abbey, M. G. Meloy, J. Blackburn, and V. D. R. Guide, "Consumer markets for remanufactured and refurbished products," California Management Review, vol. 57, no. 4, pp. 26-42, 2015.

[6] T. Shi, D. Chhajed, Z. Wan, and Y. Liu, "distribution channel choice and divisional conflict in remanufacturing operations," Production and Operations Management, vol. 29, no. 7, pp. 1702-1719, 2020.

[7] Refurbished EOS Interchangeable Lens Cameras, https:// shop.usa.canon.com/shop/en/catalog/cameras/refurbishedeos-interchangeable-lens-cameras (2020).

[8] W. Yan, Y. Xiong, Z. Xiong, and N. Guo, "Bricks vs. clicks: which is better for marketing remanufactured products?" European Journal of Operational Research, vol. 242, no. 2, pp. 434-444, 2015.

[9] Featured Reseller Partners, https://na.panasonic.com/us/ featured-reseller-partners-0 (2020).

[10] R. C. Savaskan, S. Bhattacharya, and L. N. Van Wassenhove, "Closed-loop supply chain models with product remanufacturing," Management Science, vol. 50, no. 2, pp. 239-252, 2004.

[11] L. Sun, L. Zhang, and Y. Li, "Sustainable decisions on product upgrade confrontations with remanufacturing operations," Sustainability, vol. 10, no. 11, p. 4090, 2018.

[12] M. Huang, P. Yi, and T. Shi, "Triple recycling channel strategies for remanufacturing of construction machinery in a retailer-dominated closed-loop supply chain," Sustainability, vol. 9, no. 12, p. 2167, 2017.

[13] Z.-J. Ma, Q. Zhou, Y. Dai, and G.-F. Guan, "To license or not to license remanufacturing business?” Sustainability, vol. 10, no. 2, p. 347, 2018.

[14] Z. Zou, F. Wang, X. Lai, and J. Hong, "How does licensing remanufacturing affect the supply chain considering customer environmental awareness?" Sustainability, vol. 11, no. 7, p. $1898,2019$.

[15] A. Atasu and L. N. Wassenhove, "An operations perspective on product take-back legislation for E-waste: theory, practice, and research needs," Production and Operations Management, vol. 21, no. 3, pp. 407-422, 2012.

[16] A. Atasu, L. N. Van Wassenhove, and M. Sarvary, "Efficient take-back legislation," Production and Operations Management, vol. 18, no. 3, pp. 243-258, 2009.

[17] E. Plambeck and Q. Wang, "Effects of E-waste regulation on new product introduction," Management Science, vol. 55, no. 3, pp. 333-347, 2009.

[18] A. Atasu and R. Subramanian, "Extended producer responsibility for E-waste: individual or collective producer responsibility?" Production and Operations Management, vol. 21, no. 6, pp. 1042-1059, 2012.

[19] G. Esenduran, E. Kemahlığlu-Ziya, and J. M. Swaminathan, "Take-back legislation: consequences for remanufacturing and environment," Decision Sciences, vol. 47, no. 2, pp. 219-256, 2016.

[20] G. Esenduran, E. Kemahlığlu-Ziya, and J. M. Swaminathan, "Impact of take-back regulation on the remanufacturing industry," Production and Operations Management, vol. 26, no. 5, pp. 924-944, 2017.

[21] W.-Y. K. Chiang, D. Chhajed, and J. D. Hess, "Direct marketing, indirect profits: a strategic analysis of dual-channel supply-chain design," Management Science, vol. 49, no. 1, pp. 1-20, 2003. 
[22] G. Cai, "channel selection and coordination in dual-channel supply chains," Journal of Retailing, vol. 86, no. 1, pp. 22-36, 2010.

[23] R. C. Savaskan and L. N. Van Wassenhove, "Reverse channel design: the case of competing retailers," Management Science, vol. 52, no. 1, pp. 1-14, 2006.

[24] A. Atasu and G. C. Souza, "How does product recovery affect quality choice?" Production and Operations Management, vol. 22, no. 4, pp. 991-1010, 2013.

[25] J. Bian, X. Guo, and K. W. Li, "Decentralization or integration: distribution channel selection under environmental taxation," Transportation Research Part E: Logistics and Transportation Review, vol. 113, pp. 170-193, 2018.

[26] G. Raz, C. T. Druehl, and V. Blass, "Design for the environment: life-cycle approach using a newsvendor model," Production and Operations Management, vol. 22, no. 4, pp. 940-957, 2013.

[27] A. Örsdemir, E. Kemahlığlu-Ziya, and A. K. Parlaktürk, "Competitive quality choice and remanufacturing," Production and Operations Management, vol. 23, no. 1, pp. 48-64, 2014.

[28] L. G. Debo, L. B. Toktay, and L. N. Van Wassenhove, "Market segmentation and product technology selection for remanufacturable products," Management Science, vol. 51, no. 8, pp. 1193-1205, 2005.

[29] Y. Chen and F. Chen, "On the competition between two modes of product recovery: remanufacturing and refurbishing," Production and Operations Management, vol. 28, no. 12, pp. 2983-3001, 2019.

[30] G. Esenduran, L. X. Lu, and J. M. Swaminathan, "Buyback pricing of durable goods in dual distribution channels," Manufacturing \& Service Operations Management, vol. 22, no. 2, pp. 412-428, 2020. 